\title{
Fault Detection based on MCSA for a 400Hz Asynchronous Motor for Airborne Applications
}

\author{
Steffen Haus ${ }^{1}$, Heiko Mikat ${ }^{2}$, Martin Nowara ${ }^{3}$, Surya Teja Kandukuri ${ }^{4}$, Uwe Klingauf ${ }^{5}$, and Matthias Buderath ${ }^{6}$ \\ 1,3,5 Institute of Flight Systems and Automatic Control, Technische Universität Darmstadt, Darmstadt, Hessen, 64287, Germany \\ haus@fsr.tu-darmstadt.de \\ nowara@fsr.tu-darmstadt.de \\ klingauf@fsr.tu-darmstadt.de \\ 2,6 Cassidian, Manching, Bayern, 85077, Germany \\ heiko.mikat@cassidian.com \\ matthias.buderath@cassidian.com \\ ${ }^{4}$ Cassidian, Bangalore, 560016, India \\ surya-teja.kandukuri@cassidian.com
}

\begin{abstract}
Future health monitoring concepts in different fields of engineering require reliable fault detection to avoid unscheduled machine downtime. Diagnosis of electrical induction machines for industrial applications is widely discussed in literature. In aviation industry, this topic is still only rarely discussed. A common approach to health monitoring for electrical induction machines is to use Motor Current Signature Analysis (MCSA) based on a Fast Fourier Transform (FFT). Research results on this topic are available for comparatively large motors, where the power supply is typically based on $50 \mathrm{~Hz}$ alternating current, which is the general power supply frequency for industrial applications.

In this paper, transferability to airborne applications, where the power supply is $400 \mathrm{~Hz}$, is assessed. Three phase asynchronous motors are used to analyse detectability of different motor faults. The possibility to transfer fault detection results from $50 \mathrm{~Hz}$ to $400 \mathrm{~Hz}$ induction machines is the main question answered in this research work. $400 \mathrm{~Hz}$ power supply frequency requires adjusted motor design, causing increased motor speed compared to $50 \mathrm{~Hz}$ supply frequency. The motor used for experiments in this work is a $800 \mathrm{~W}$ motor with $200 \mathrm{~V}$ phase to phase power supply, powering an avionic fan. The fault cases to be examined are a bearing fault, a rotor unbalance, a stator winding fault, a broken rotor bar and a static air gap eccentricity. These are the most common faults in electrical induction machines which can cause machine downtime.

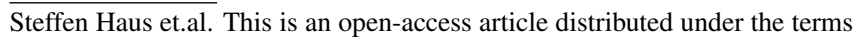
of the Creative Commons Attribution 3.0 United States License, which permits unrestricted use, distribution, and reproduction in any medium, provided the original author and source are credited.
}

The focus of the research work is the feasibility of the application of MCSA for small scale, high speed motor design, using the Fourier spectra of the current signal.

Detectability is given for all but the bearing fault, although rotor unbalance can only be detected in case of severe damage level. Results obtained in the experiments are interpreted with respect to the motor design. Physical interpretation are given in case the results differ from those found in literature for $50 \mathrm{~Hz}$ electrical machines.

\section{INTRODUCTION}

Health monitoring has gained major attention in various sectors of engineering over the last two decades. As an example, (Thomson \& Gilmore, 2003) exposes the financial and production losses due to unscheduled downtime of production plants, where large size induction motors are often used. This argumentation can easily be transferred to the aviation sector, where unscheduled maintenance due to malfunction of small size induction motors potentially forces the aircraft to stay on ground. Unscheduled maintenance events result in financial losses for airlines and therefore is of high interest to be prevented by applying innovative diagnosis and prognosis algorithms at component level. Penalty cost analysis within aviation industry is examined in (Knotts, 1999), where e.g. the cost for a delayed Boeing 747 is specified with $600 \$$ per minute. Furthermore, the author states that $20 \%$ of Boeing $747 \mathrm{~s}$ delays are caused by technical issues. In (Fritzsche \& Lasch, 2012), the advantages of a Prognostics and Health Management (PHM) scheduled maintenance are shown. Strategies are shown in order to minimize the cost 
for unscheduled downtime. These publications clearly show the motivation to increase aircraft availability by reducing unscheduled maintenance events. This could be achieved by applying reliable diagnosis and prognosis algorithms to aircraft components.

In the area of health assessment for electrical induction machines, two main approaches for diagnosis algorithms are found in literature: analysis of acceleration signals and analysis of current signals. Primarily, acceleration sensors were used to monitor the motor vibration and to evaluate the motor health grade, an approach which has proven to give accurate results especially on bearing faults in induction machines. An alternative monitoring concept is to measure the current signals of induction machines.

Current sensors usually offer a cost advantage over acceleration sensors and furthermore can be integrated in the component power supply line with no need to be installed directly at the motor housing. Considering an airborne application, current sensors have two more advantages over the acceleration sensors. First, the measured signals are independent from conditions in the surrounding area which could cause faulty results due to structural vibration and due to flight attitude at high load factor. Second, sensor reliability is not degraded because of the above mentioned reasons.

These advantages of the current sensors led to high quality publications of numerous research results in the field of motor current signature analysis (MCSA). Examples for Fast Fourier Transform (FFT) based diagnosis of asynchronous motors using the current signals only, whereon parts of this research work is based on, are mentioned here. In (El Hachemi Benbouzid, 2000), a review of MCSA for induction motors is given. Therein, typical fault cases are examined and, amongst others, a classical FFT based diagnosis concept is described. (MEHALA, 2010) also uses FFT transformation of the current signals and various other approaches to detect failures in a three phase asynchronous motor. The procedure of the FFT based fault detection in these publication is similar, using a notch filter to reduce the supply frequency of the measured current signal. Thereafter, the filtered current signal is transformed in frequency domain and characteristic peaks are evaluated to determine the health grade of the motor. Comparable FFT analysis for large size induction motors are presented in (Thomson, Rankin, \& Dorrell, 1999; Thomson, 2001; Thomson \& Gilmore, 2003), where furthermore the need for diagnosis of large scale motors in industrial applications is explained.

The above mentioned publications have in common, that fault diagnosis based on MCSA is examined using $50 \mathrm{~Hz}$ or in a few cases $60 \mathrm{~Hz}$ power supply systems, as they are used for industrial applications. This electric frequency results in slow motor speed. Furthermore, the research results found in literature seldom focus on motors with less than $1 \mathrm{~kW}$ power.
However, the airborne power supply system is still mostly based on $400 \mathrm{~Hz}$ alternating current. This leads to adapted design of induction motors, resulting in smaller motors with faster rotor speed. Given the same number of pole pairs, a $400 \mathrm{~Hz}$ asynchronous motor has approx. eight times higher rotor speed than a $50 \mathrm{~Hz}$ motor. Additionally, aviation certification ensures high quality and reliable component design. Nevertheless, unexpected component failures even of non safety relevant components can cause unscheduled ground time. Differences in the design of induction motors used in industry $(50 \mathrm{~Hz} / 60 \mathrm{~Hz}$ power supply) and in aviation $(400 \mathrm{~Hz}$ power supply) are existent, mainly because of different supply frequency. The discussion in this paper covers the question, if fault diagnosis results using FFT based MCSA can be transferred to aviation components. Scientific results on FFT based MCSA diagnosis of $400 \mathrm{~Hz}$ induction motors are not found in literature. The results of this paper provide the basis for future health monitoring systems for electrical machines in aviation industry. Data collection, data processing and interpretation are essential for reliable upcoming diagnosis and prognosis concepts.

This research work therefore analyses and discusses the transferability of the results in FFT based MCSA from $50 \mathrm{~Hz}$ to $400 \mathrm{~Hz}$ motor design. Furthermore, the motors used in the experiments are of $0.8 \mathrm{~kW}$ power, which corresponds to a comparable low power class for motors of this design in airborne applications. Problems arising in MCSA using FFT transformed current signals due to the small power class are examined. The motors used are three phase asynchronous motors, e.g. powering a cabin evaporator fan of a Boeing 737. The component has aviation certification, giving application oriented results. The sensor configuration used in the test rig is designed without needing a component redesign because the sensors are placed in the cable connection between power supply and component. Availability of previously certificated components can be increased using the proposed sensor configuration. Up to four motors are used for the test runs, allowing an evaluation containing series deviation, which is present in all parts. This work includes five different fault cases, i.e. bearing fault, rotor unbalance, stator winding fault, broken rotor bar and static air gap eccentricity.

\section{MONitoring ConCEPT}

A change of the magnetic flux in an asynchronous motor causes an induced current flow into the power supply line. This induced current can be detected using current sensors monitoring the line currents of the motor connectors. Magnetic flux changes arise in case of two reasons:

- change of the air gap between stator and rotor

- change of the electrical part of the motor

A variation in the air gap can appear due to mechanical load on the rotor, e.g. due to an unbalanced rotor. A change in 
the electrical motor parts, e.g. a defective rotor cage or a defective stator, also lead to an induced line current. These physical basic principles enable a monitoring concept using current sensors only to detect both mechanical and electrical faults.

The sensors used in this research project are hall sensors, giving a galvanic separation of measurement system and component wiring. Using this monitoring concept, only the cable connection to the motor is modified, so that no redesign of the component itself is required. This is an important advantage of this sensor type for an airborne application since expensive and extensive renewal of the component certification is not necessary.

The current sensors are sampled at a rate of $25 \mathrm{kHz}$. The sampling rate is sufficient to avoid aliasing effects for the expected fault frequencies. Furthermore, a speed sensor is integrated in the motors. The speed signal is needed to calculate the characteristic fault frequencies of the respective failure cases. The health monitoring concept suggested in this research work is to compare the frequency spectra of a faulty motor to spectra of motors in delivery state. For the assessment of the health grade of the motor (motor degradation), the current magnitude of the peak at the respective characteristic fault frequencies are compared to those in delivery state. Therefore, the magnitude of the current signal at the characteristic fault frequencies serve as features for the diagnosis approach to detect motor failures.

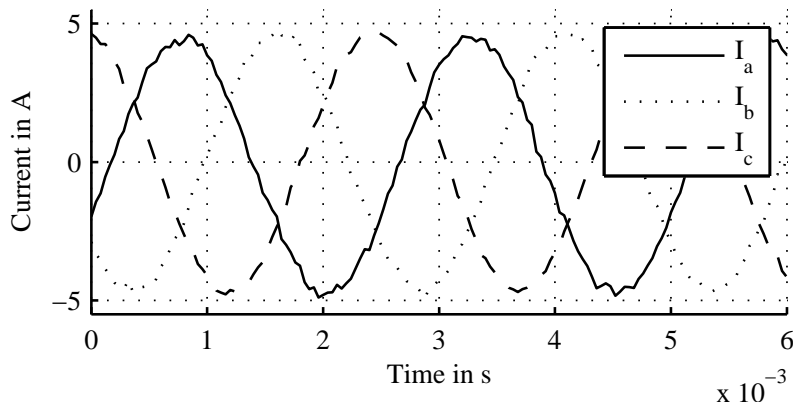

Figure 1. Measured current signals of all phases

An example of the measured current signal of all three phases is shown in Figure 1. The signal to noise ratio (SNR) of the measured data is $\mathrm{SNR}>600$, providing measured data with sufficient accuracy.

\subsection{Data Acquisition and Preprocessing}

Data are measured using a PC with Matlab/Simulink and DSpace at a sample rate of $25 \mathrm{kHz}$. The measurement length is 5 seconds. A notch filter is used to attenuate the supply frequency of $400 \mathrm{~Hz}$. The notch filter is designed as a Butterworth-Filter of $6^{\text {th }}$ order with a bandwidth of $8 \mathrm{~Hz}$. Since this filter is a dynamic system with transient behavior, the first $500 \mathrm{~ms}$ of every cycle are spared out, using only the last 4.5 seconds of every measurement for the diagnosis. To correct the data for sensor bias, the mean value of the filtered current signal is subtracted from every measured signal. Furthermore, a hanning window is used to preprocess the data in order to achieve clearer spectra by reducing leakage effects. Finally, the data in time domain are transferred into frequency domain by using a FFT algorithm. The spectra in frequency domain are the basis for the diagnosis. The 4.5 seconds of measured data comprises 112,500 samples, giving to a resolution of the frequency axis of $0.191 \mathrm{~Hz}$.

\subsection{Diagnosis Algorithm}

In this subsection, a brief overview of the diagnosis algorithm which is going to be applied based on the results of this research work, is given. This work concentrates on the feasibility to diagnose faults on a small sized motor with $400 \mathrm{~Hz}$ (airborne) power supply, but not on the application of an extensive health monitoring. The proposed approach is therefore a mere standard approach. Nevertheless, the results can easily be integrated into a functioning health monitoring software.

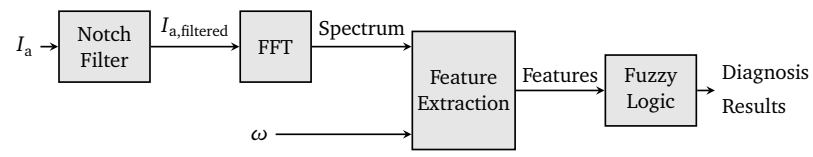

Figure 2. Structure of the proposed diagnosis algorithm

The design of the health monitoring concept is depicted in Figure 2. A current signal is filtered using a notch filter and transferred in frequency domain. In this case, the motor current $I_{a}$ of phase A is used but could be replaced by phase B or C. Changing the phase used for diagnosis changes nothing in fault cases with rotating damage characteristic (inner ring bearing damage, rotor unbalance, broken rotor bar). Using a different phase for fault detection could cause some minor changes in the current magnitudes of stator fixed damage cases (outer ring bearing fault, stator winding fault, static air gap eccentricity).

Using the Fourier spectrum of the latest sampled data and the average rotor speed $\omega$ of the respective time range, features are extracted. The features are the magnitudes of Fourier spectrum at the characteristic fault frequencies. These fault frequencies are calculated using the rotor speed. The feature characteristic of the motor in delivery state is examined in section 4 , while the analysis of the detectability of motor faults using these features is the main topic of section 5. Furthermore, a Fuzzy Logic is suggested to interpret the features and output the results of the diagnosis algorithm. The implementation, testing and analysing of the proposed diagnosis algorithm is the subject of ongoing research projects. 
Additional functionality using three current sensors could be implemented concerning self diagnostic capabilities. The confidence in the diagnosis results could be increased by using and comparing the results from more than one sensor and even sensor faults itself could possibly be detected. Furthermore, the standard diagnosis approach of monitoring the current Park's vectors needs the current signals of all three phases, see e.g. (Marques Cardoso, Cruz, \& Fonseca, 1999).

\section{TEST SETUP}

The test rig is powered using a variable voltage, variable frequency power supply. It is set to $115 \mathrm{~V}$ line to ground which is $200 \mathrm{~V}$ line to line and synchronised at a phase angle of 120 . The motor is a three phase wye-connected asynchronous motor with no neural wire. The motor powers a fan, consuming approx. $800 \mathrm{~W}$ under normal condition. During run-up, the motor consumes more power but this operating point is not considered in the following analysis. The motor has a rated speed of $11300 \mathrm{rpm}$ which is approx. $188 \mathrm{~Hz}$. The fan is installed in an open tube system with the in- and outflow connected to outdoor air. The inflow tube is flexible, which is a realistic assembly. Behind the fan, an air regulator is used to control the airflow to a constant of 235 liter per second. The airflow is measured using a flow sensor. The air flow is controlled using a PI feedback controller. All experiments are carried out at a constant set point of $235 \mathrm{l} / \mathrm{s}$, if not mentioned otherwise. The speed sensor is integrated in the motor, supplied by the manufacturer. The complete test rig installation is attached to a machine test bed. A schematic picture of the test rig with installed motor (Unit Under Test, UUT) is shown in Figure 3. The protection cover is installed for safety reasons.

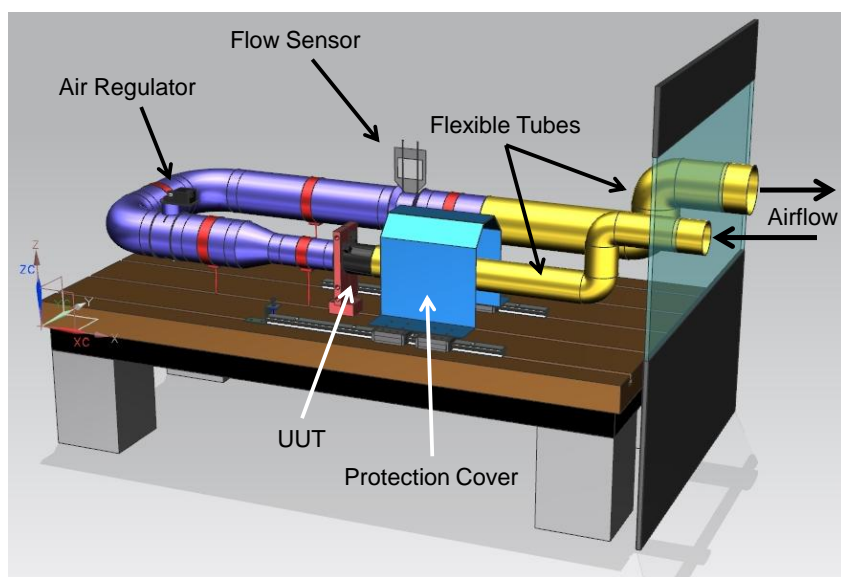

Figure 3. Schematic picture of the test rig

\section{Spectral Analysis of Motor in Delivery STATE}

The frequency spectra of the motors in delivery state are the subject of this section. The motor is assumed to be in delivery state as long as no parts are replaced or damaged during the test procedure. These spectra are used as basis of comparison for the spectra obtained by analysing the current spectra of faulty motors. More precisely, the current amplitudes at the characteristic fault frequencies of faulty motors are compared to those determined in this section. The data are measured every 20 seconds and the spectra shown in this analysis are measured when the motor operates in steady state. For every relevant case, one representative spectra is shown.

First, the spectrum of one motor in delivery state is discussed. In subsection 4.1 , the differences of the spectra from different motors in delivery state are examined. Figure 4 shows the Fourier spectrum of one motor (index \#1) in delivery state. Only the frequencies up to $6 \mathrm{kHz}$ are considered since no peaks appeared above in this entire analysis. The magnitude peak at exactly $2 \mathrm{kHz}$ is produced by the power supply and is therefore not discussed any further. The power supply also

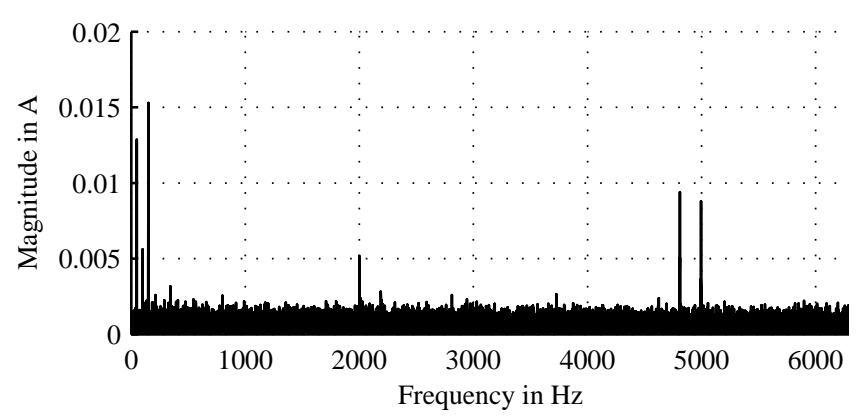

Figure 4. Spectrum of motor in delivery state

causes peaks at 50, 100 and $150 \mathrm{~Hz}$. These peaks are shown in Figure 5, where the frequency axis is cropped from 0 to $380 \mathrm{~Hz}$. These peaks are not further considered since they appear in every measurement and are not caused by motor effects but by the power supply. In this frequency range, characteristic fault frequencies which proved to be of great interest in this research work appear at 214 and $344 \mathrm{~Hz}$, as marked in the graph. The peak at $214 \mathrm{~Hz}$ appears in the characteristic fault frequencies of the stator winding fault (STF) and of the dynamic air gap eccentricity (AGE). The peak at $344 \mathrm{~Hz}$ belongs to the characteristic fault frequency of the broken rotor bar (BRB) fault. Explanations and formulas for the respective characteristic fault frequencies are given in section 5 .

The frequency range between 380 and $600 \mathrm{~Hz}$ is shwon in Figure 6. The effect of the notch filter at $400 \mathrm{~Hz}$ is obvious, no measurement noise is visible at this frequency and the supply frequency is efficiently damped. Another important frequency is at $586 \mathrm{~Hz}$, where also characteristic fault frequency 


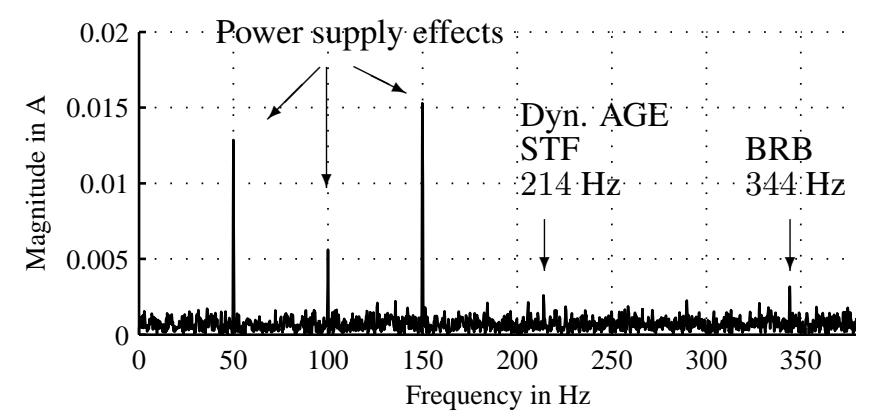

Figure 5. Delivery state, 0 to $380 \mathrm{~Hz}$

of STF and AGE are appearing in some measurements. In this particular test run, no peak is visible. This phenomenon will be discussed in subsection 4.1. All spectra of fans in

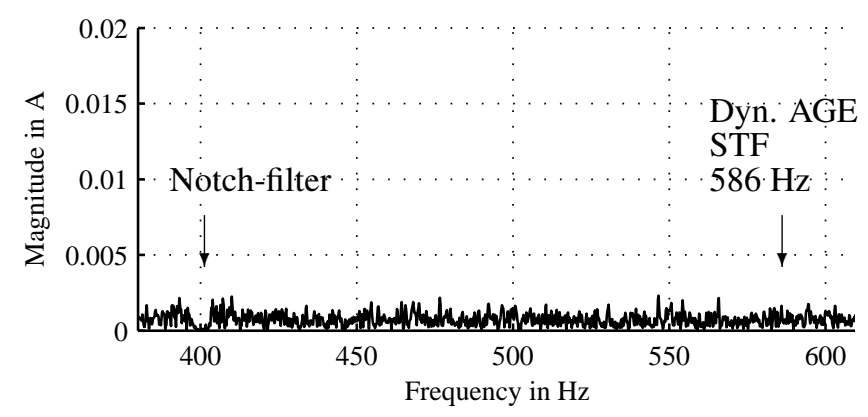

Figure 6. Delivery state, 380 to $600 \mathrm{~Hz}$

delivery state show nothing but measurement noise in the range from $586 \mathrm{~Hz}$ to approx. $4800 \mathrm{~Hz}$. Important peaks in the Fourier spectra are found around $5 \mathrm{kHz}$, as shown in Figure 7. The peaks at $4809 \mathrm{~Hz}$ appears in the dynamic- and the peak at $4995 \mathrm{~Hz}$ in the characteristic fault frequency of the static AGE. Dynamic AGE can e.g. be the result of an unbalanced rotor. Both peaks are appearing in most spectra, also in those of motors in delivery state.

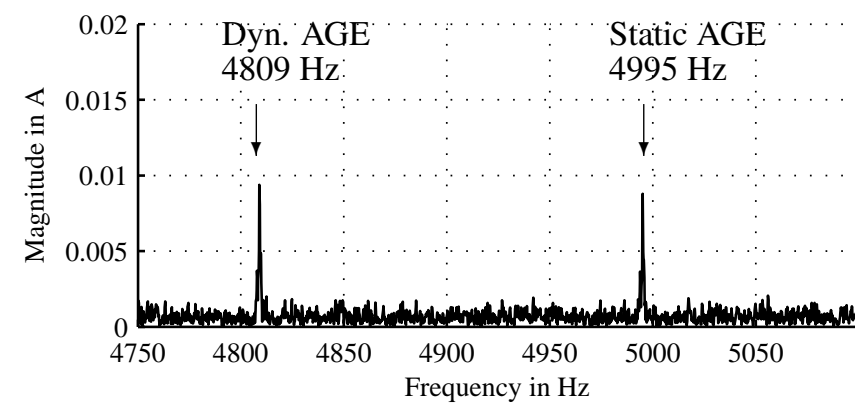

Figure 7. Delivery state, 4800 to $5100 \mathrm{~Hz}$

Note that most peaks of the characteristic fault frequencies are dependent on the rotor speed. An example is the peak of the dynamic AGE fault at approx. $4800 \mathrm{~Hz}$. Figure 8 shows these peaks of consecutive measured spectra in the frequency range of this characteristic frequency, as viewed from the top of the spectra. It is clearly visible that the frequency of the peak shifts over time. The frequency converges after approx. 400 seconds. The additional lines appearing in the plot are the result of sensor noise and are of no interest. Therefore, the

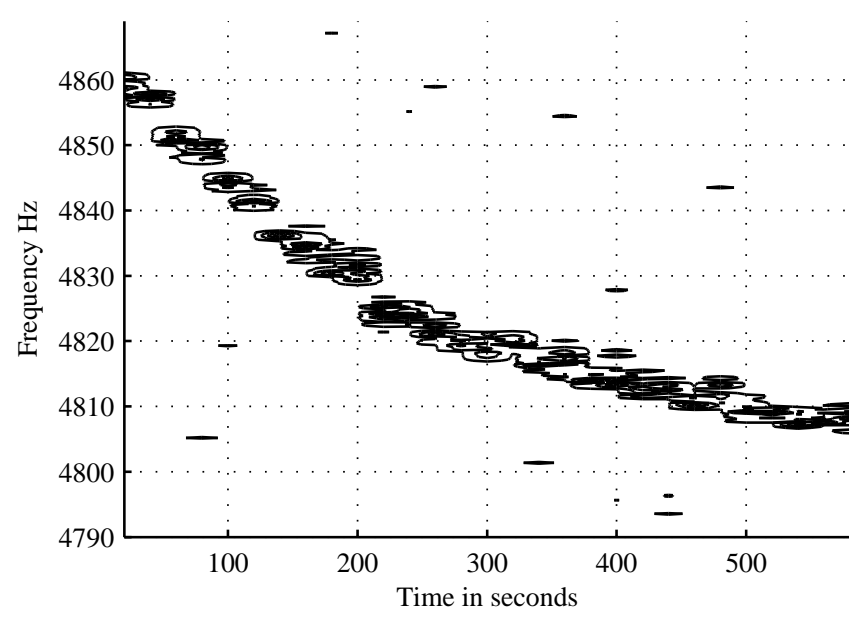

Figure 8. Shifting of dynamic AGE peak due to changing rotor speed

frequency search range for every fault case has to be adjusted based on the actual rotor speed. The spectra shown above are measured using motor \#1. Differences between the motors in delivery state will be discussed in the following subsection.

\subsection{Series Deviation}

Although the motors are certificated for aviation applications which ensures high quality design and precise manufacturing, differences in the current signals are appearing in delivery state. Note that all acceptance tests by the manufacturer are accomplished. Current signature analysis is not within the acceptance test procedure.

The frequency ranges which turned out to be of interest for the motor health assessment are listed with the respective fault case in the first two columns of Table 1. These frequencies are the basis for the analysis in section 5 .

\begin{tabular}{l|c|c|c|c|c}
\hline \hline Fault case & $\begin{array}{c}\text { Freq. } \\
\text { in Hz }\end{array}$ & $\begin{array}{c}\text { Motor } \\
\# 1\end{array}$ & $\begin{array}{c}\text { Motor } \\
\# 2\end{array}$ & $\begin{array}{c}\text { Motor } \\
\# 3\end{array}$ & $\begin{array}{c}\text { Motor } \\
\# 4\end{array}$ \\
\hline \hline STF, dyn. AGE & 214 & 4 & 5 & - & - \\
\hline BRB & 344 & 3 & 7 & 12 & 10 \\
\hline STF, dyn. AGE & 586 & 2.5 & - & - & - \\
\hline Dyn. AGE & 4809 & 10 & 4 & 4 & 5 \\
\hline Static AGE & 4995 & 10 & 4 & 2 & 6 \\
\hline
\end{tabular}

Table 1. Maximum peaks in current spectra in $\mathrm{mA}$

Figures $9,10,11$ show the frequency ranges of interest for the motors \#2, \#3, \#4, respectively. The frequencies where peaks 
are appearing or expected are marked. These plots clearly show the differences in the current amplitudes for the different motors.
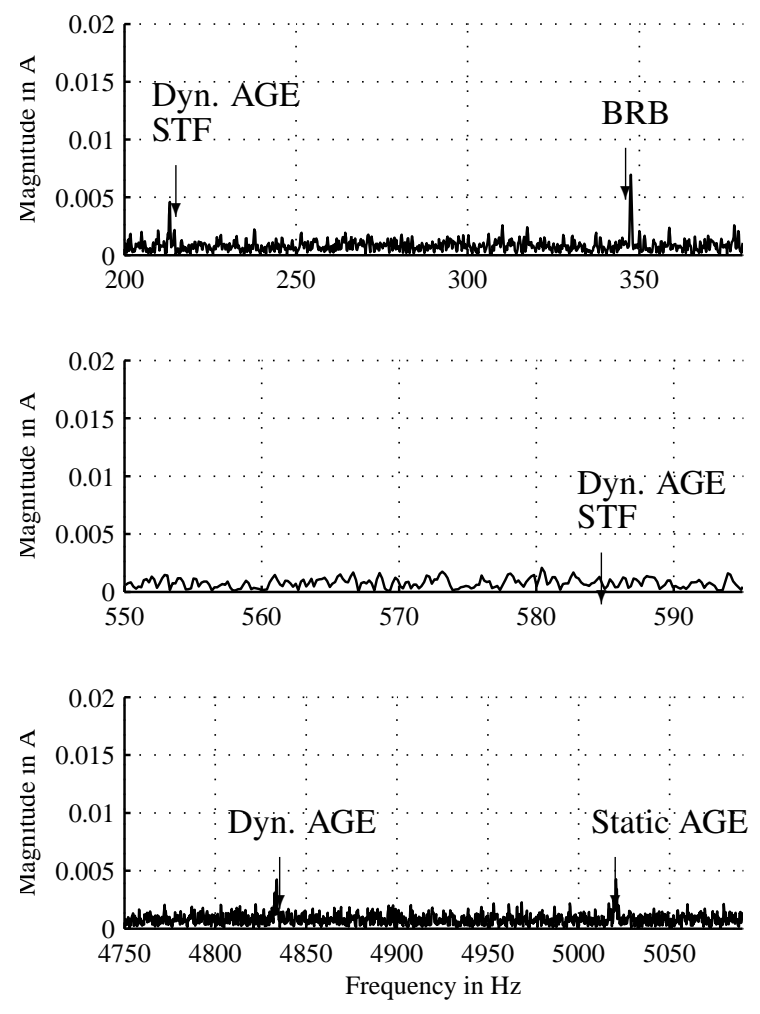

Figure 9. Spectrum of motor \#2 in delivery state

Table 1 lists the maximum peaks occurring during the analysis of the motors in delivery state. The table identifies the peak at the characteristic fault frequency of the broken rotor bar as the one with the most differing current magnitudes in delivery state. The reason for this observation can be found in imperfect production. Also the peaks around $214 \mathrm{~Hz}$ differ significantly. Furthermore, motor \#1 shows major anomalies compared to the other motors. Differences in the current magnitude of the static AGE frequencies can also be caused by imperfect installation. This effect can also be caused during disassembling and assembling of the motors during the test procedures. The results obtained during the analysis of the motor spectra and their variance in delivery state serve as basis for comparison to the faulty motors.

To be further mentioned, the frequency spectra show sensor noise with approx. $2 \mathrm{~mA}$. This makes all peaks below $2 \mathrm{~mA}$ being interpreted as sensor noise. This can be seen e.g. in Figure 4.
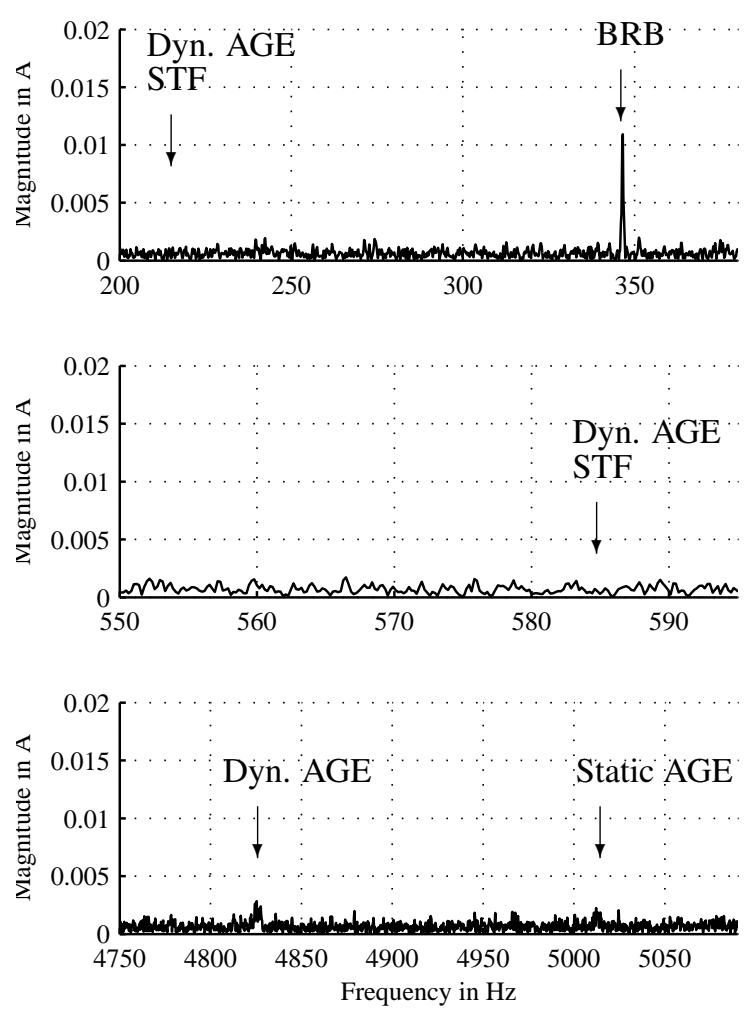

Figure 10. Spectrum of motor \#3 in delivery state
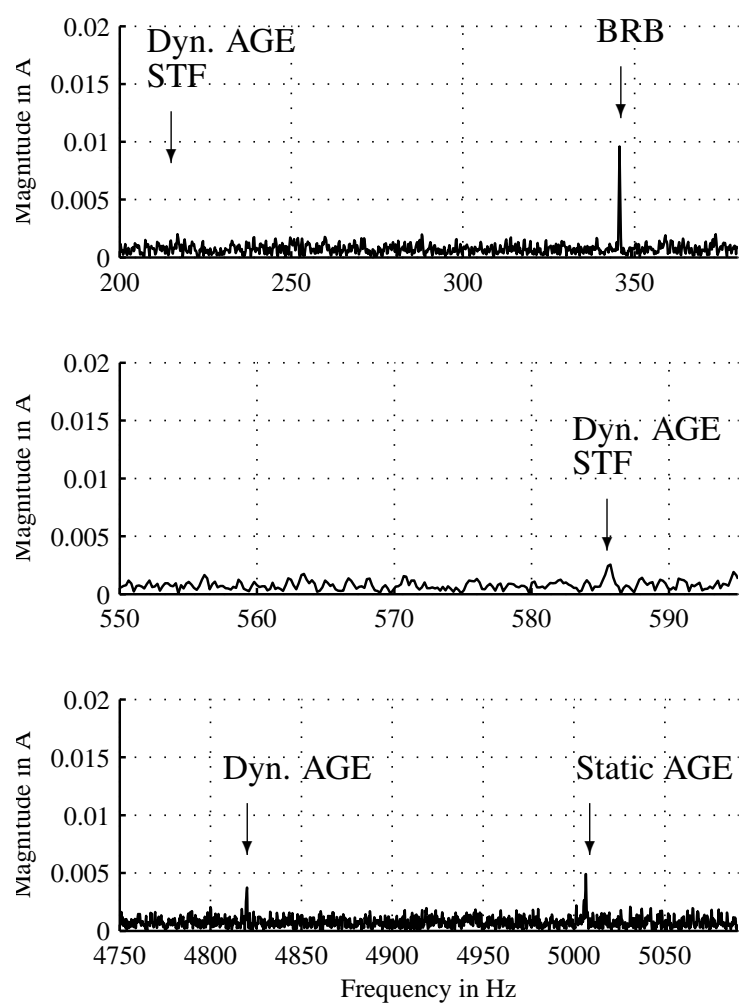

Figure 11. Spectrum of motor \#4 in delivery state 


\section{Failure Cases and analysis}

The main section of this research work describes the fault insertion and the spectral failure analysis of the most relevant fault modes of an asynchronous motor. The section is split in five subsections for the respective fault cases. The characteristic fault frequencies are explained and the obtained results are examined with respect to the small size, high speed and high quality motor design. Analysis and interpretation concentrate on the specific characteristics which comes due to the $400 \mathrm{~Hz}$ motor design and the small size and motor power class.

\subsection{Bearing Failure}

A relatively common fault in rotating machinery is a defective bearing (Saadaoui \& Jelassi, 2008; Blodt, Granjon, Raison, \& Rostaing, 2008). The author in (Schoen, Habetler, Kamran, \& Bartfield, 1995) states, that over $40 \%$ of all motor failures are caused by bearing problems. Bearing failures (BRG) can be distinguished in defective inner- or outer rings. It was shown, that FFT based MCSA could successfully detect defective bearings for induction motors powered by $50 \mathrm{~Hz}$ alternating current (MEHALA, 2010), but to the author no research work detecting bearing faults using FFT based MCSA for $400 \mathrm{~Hz}$ motors is known. Bearing failures can occur due to inappropriate load. This could e.g. be the result of an unbalanced rotor or of an increased preload.

The rotors used for this research work are supported by two ball bearings, the bearing close to the inflow of the fan is further on labelled as front bearing, the other as rear bearing. During the test campaign, both failure modes were artificially induced using mill tools. First of all it has to be mentioned that the bearing fault for the small size, high speed rotor used in these experiments could not be detected using the Fourier spectra of the current signal. Nevertheless, the measured data are shown, reasons and interpretations for the unexpected results and an outlook to detect this particular fault case are given.

\subsubsection{Characteristic BRG Fault Frequencies}

The formulas for approximated inner- and outer characteristic bearing fault frequencies can e.g. be found in (Benbouzid \& Kliman, 2003; Blodt et al., 2008; Nandi, Toliyat, \& Li, 2005) and are given by

$$
f_{\mathrm{BRG}}=\left|f_{\mathrm{s}} \pm m \cdot f_{\mathrm{ir}, \mathrm{or}}\right|
$$

where $f_{\mathrm{BRG}}$ are the characteristic fault frequency for bearing damage, $f_{\mathrm{s}}$ is the supply frequency which is $400 \mathrm{~Hz}$ for this motor, $m$ is any integer, $f_{i r}$ and $f_{\text {or }}$ are characteristic frequencies for inner and outer ring. For an exact calculation, extensive knowledge of the bearing design is required, but these frequencies are commonly approximated by

$$
\begin{gathered}
f_{\text {ir }}=0.6 N_{\mathrm{b}} f_{\mathrm{r}} \\
f_{\text {or }}=0.4 N_{\mathrm{b}} f_{\mathrm{r}}
\end{gathered}
$$

with $N_{\mathrm{b}}$ as number of bearing balls and $f_{\mathrm{r}}$ as rotor speed. Given a rated rotor speed of $188 \mathrm{~Hz}$, the formulas above lead to the characteristic fault frequencies for $N_{\mathrm{b}}=7$ as shown in Table 2.

\begin{tabular}{c|r|r}
\hline \hline $\mathbf{m}$ & $f_{\text {ir in } \mathrm{Hz}}$ & $f_{\text {or }}$ in $\mathrm{Hz}$ \\
\hline \hline 1 & 1189.6 & 926.4 \\
\hline-1 & 396.6 & 126.4 \\
\hline 2 & 1979.2 & 1452.8 \\
\hline-2 & 1179.2 & 652.8 \\
\hline
\end{tabular}

Table 2. Characteristic fault frequencies for BRG fault

\subsubsection{Spectral Analysis for Inner Ring BRG Fault}

The damage in the inner ring is induced using an angle grinder, see Figure 12. The defective inner bearing ring was installed both in the front and in the rear bearing for separate test runs and for different motors. The current spectra

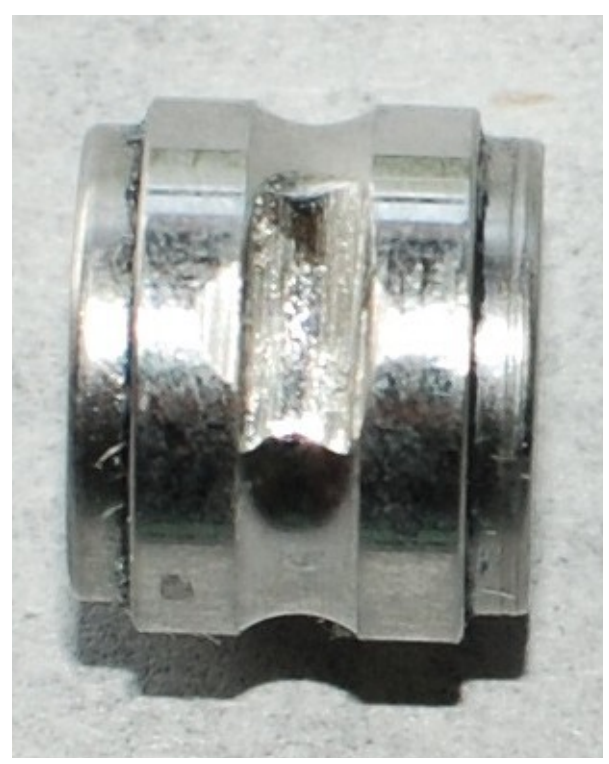

Figure 12. Inner ring BRG damage

around the calculated characteristic fault frequencies for the inner ring damage (installed in the rear bearing) are shown in Figure 13. The characteristic fault frequencies, the Notch filter frequency and the peak caused by the power supply are marked. Unfortunately, the defective bearing can not be detected using the Fourier transform of the current signal with the proposed sensor concept. No increased current magnitude is visible in the spectra at the expected characteristic fault frequencies. Furthermore, extensive scanning of the current spectra show no other differences compared to the spectra obtained using motors in delivery state. The results are 
repeatable by installing the damaged inner ring in a different motor or in the front bearing. The conclusion has to be that the defective inner bearing ring can not be detected in the current spectra using the magnitude of the characteristic fault frequencies for this motor.
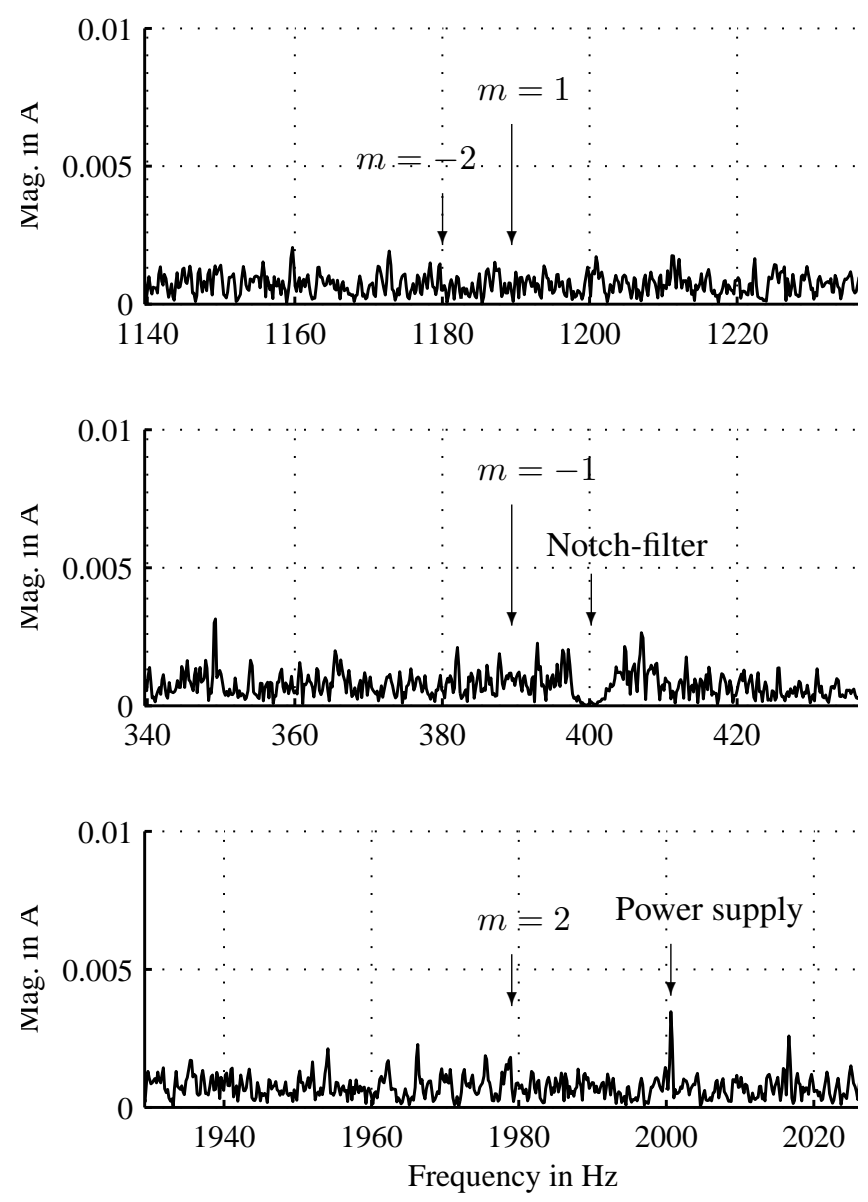

Figure 13. Inner ring BRG damage

\subsubsection{Spectral Analysis for Outer Ring BRG Fault}

The damage in the inner ring is induced using an angle grinder, see Figure 14. As done with the damaged inner ring, the defective outer bearing ring was installed both in the front and in the rear bearing for separate test runs and for different motors. The current spectrum in the region of the characteristic fault frequencies given in Table 2 is shown in Figure 15 for a damaged outer ring in the front bearing. The characteristic fault frequencies and the peaks caused by the power supply are marked. The results for the outer ring bearing damage is equal to the result obtained for the inner ring damage, no expected peak is visible, leading to the conclusion that this failure case can not be detected in the FFT spectra of the current signal. The results can be reproduced if the defective outer ring is installed at the rear bearing.

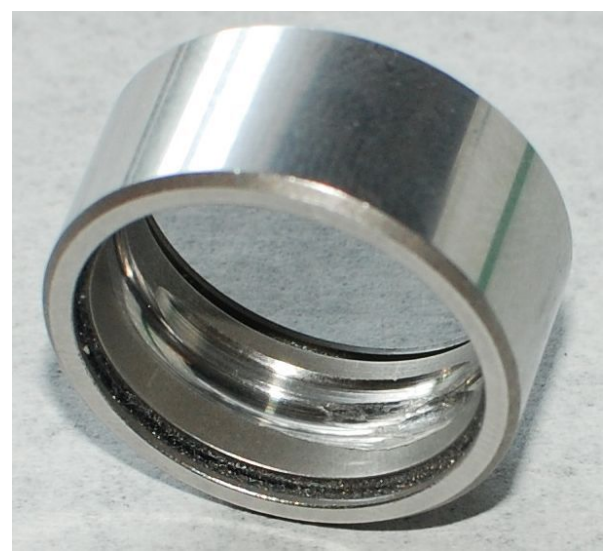

Figure 14. Outer ring BRG damage

The conclusion that the bearing damage for this particular asynchronous motor can not be detected in the Fourier spectra of the current signal could be confirmed running the motor at a different operating point. To do so, the airflow was reduced to $218 \mathrm{l} / \mathrm{s}$, forcing the air regulator to increase the resistance for the air flow. No peaks occurred in the spectra. The plots are spared out here since no additional information are found therein.

\subsubsection{Interpretations}

Many publications stated that a defective ball bearing could be detected using current sensors only by Fourier transform of the measured signal. These results for this particular fault case could not be confirmed for a small $400 \mathrm{~Hz}$ asynchronous motor, as used in this test campaign. Although running the motors with damaged bearings caused noticeable noise emission, no change in the current spectra was high enough to be detected.

The reason therefore is found in the measuring principle. In case no fault is given in the electrical part of the motor (stator fault or rotor bars), a defective motor has an influence on the current signal only if the air gap is unequal during one rotor rotation. An unequal air gap between rotor and stator causes an induced current which can be detected using current sensors. This leads to the conclusion that the change in the air gap is not affected in detectable manner by the damaged bearing. This is in contrast to the research works performed by various authors using $50 / 60 \mathrm{~Hz}$ motors, where the bearing damage could be detected reliably in the FFT spectra. See e.g. (MEHALA, 2010), where the motor speed was 1380 rpm (defective bearing, full load) which is one eights of the rotor speed of the motor used in this research work. Therein, the change in the air gap clearly was high enough to cause an induced current which was detectable. The slower rotor speed means that a bearing ball needs more time to overrun 

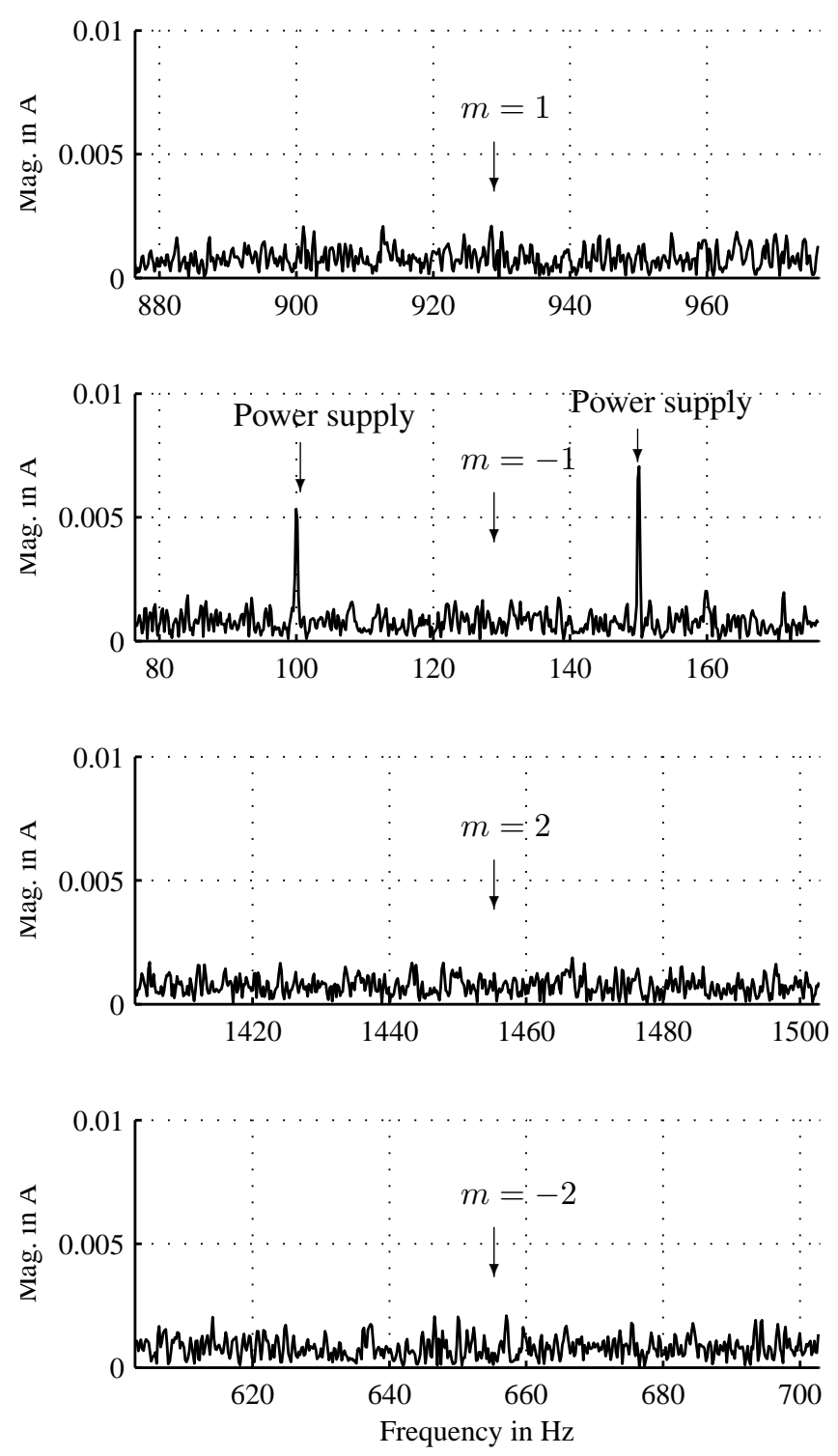

Figure 15. Outer ring BRG damage

the defective part of the bearing. Increasing the contact time between bearing balls and defective position of the bearing ring also increases the time in which the rotating parts of the motor can accelerate in radial direction. The displacement is obtained by integrating the acceleration twice, leading to larger displacement in case of slower rotor speed. Larger displacement between inner and outer bearing ring causes larger changes in the air gap. Comparing the results obtained in e.g. the above mentioned publication and this research work is, that a fast rotating motor complicates the detection of a faulty bearing. In this case, using only the FFT spectra of the current signal, a diagnosis is even not possible since the displacement between inner and outer bearing ring is too low.

An analysis of the acceleration signals confirms this theory.
The frequency spectra of the radial acceleration signal are shown in Figure 16. The upper plot shows the acceleration for a motor in delivery state, the lower for a motor with defective bearing. The acceleration is much higher for the damaged bearing with many additional peaks. However, the acceleration phase of the rotor axis in radial direction is too short to cause a movement of the axis which could be detected due to changes in the air gap using current sensors. The too short acceleration phase is the result of the fast rotating motor axis.
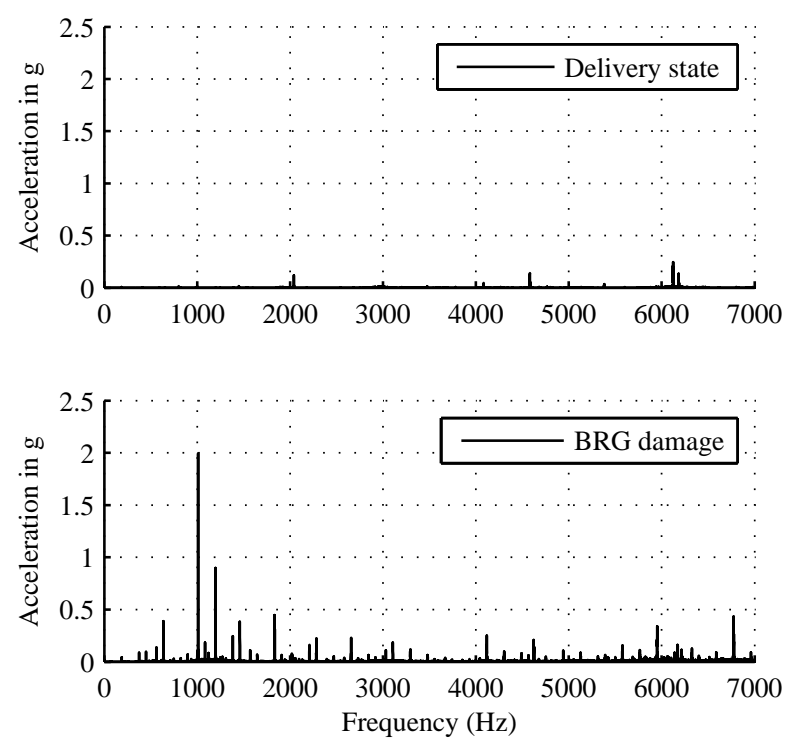

Figure 16. Acceleration signal for motor in delivery state and with defective bearing

Based on the above given analysis, the result on this particular fault case is that FFT based MCSA bearing fault detection is not recommended for fast rotating induction machines. Despite these results, further diagnosis methods are to be tested for the bearing fault. In (Lau \& Ngan, 2010), the author suggests using wavelet transform of the current signal to detect faulty bearings using MCSA. Analysis using the Hilbert space is suggested in (Ben Salem, Bacha, \& Gossa, 2012) to detect damage in the outer raceway of the ball bearing. It is still to be tested if such methods, which showed good results for low speed induction machines, can be applied to motors with $400 \mathrm{~Hz}$ power supply.

\subsection{Rotor Unbalance}

Rotor unbalance means that an eccentric mass distribution in the rotor forces the rotor axis to deflect in radial direction. This displacement causes variations in the air gap between stator and rotor which can be detected in the current signal. Since the eccentric mass rotates with the rotor speed, the changes in the air gap is dynamic, causing a dynamic air gap eccentricity (AGE). The characteristic fault frequencies for the rotor unbalance are therefore the frequencies of the dy- 
namic AGE fault. Two different methods are chosen for fault insertion and analysed. First, additional mass is attached to propeller and rotor and second, holes are drilled in the rotor of the asynchronous motor.

\subsubsection{Characteristic Dynamic AGE Fault Frequenies}

The formula for the characteristic fault frequency of the dynamic AGE fault can e.g. be found in (MEHALA, 2010). The general formula for an air gap eccentricity is

$$
f_{\mathrm{AGE}, \mathrm{dyn}}=\left(\left(n_{\mathrm{rt}} R+n_{\mathrm{d}}\right) \frac{1-s}{P}+n_{\mathrm{ws}}\right) \cdot f_{\mathrm{s}},
$$

where

$$
\begin{aligned}
n_{\mathrm{rt}} & =[0,1,2, \ldots] \\
n_{\mathrm{ws}} & =[\ldots,-5,-3,-1,1,3,5 \ldots] \\
n_{\mathrm{d}} & =[\ldots,-2,-1,0,1,2, \ldots] .
\end{aligned}
$$

The three $n$ 's in the formula give three sets of harmonics (MEHALA, 2010). $n_{\mathrm{rt}}$ is rotor related and $n_{\mathrm{ws}}$ is stator related. $n_{\mathrm{d}}$ is the eccentric order with $n_{\mathrm{d}}=0$ for the static AGE fault. The slip $s$ is given by

$$
s=1-\frac{P \cdot f_{\mathrm{r}}}{f_{\mathrm{s}}}
$$

Given a rated rotor speed of $188 \mathrm{~Hz}$, the formulas above lead to the characteristic fault frequencies for $R=29$ (number of rotor bars) and $P=2$ (number of pole pairs) as shown in Table 3. Note that the last peak shown in Table 3 is the peak

\begin{tabular}{c|c|c|r}
\hline \hline$n_{\mathbf{r t}}$ & $n_{\mathbf{d}}$ & $n_{\text {ws }}$ & $f_{\text {ir }}$ in $\mathrm{Hz}$ \\
\hline \hline 0 & 1 & 1 & 588 \\
\hline 0 & 1 & -1 & -212 \\
\hline 0 & -1 & 1 & 212 \\
\hline 0 & -1 & -1 & -588 \\
\hline 1 & 1 & 1 & 6040 \\
\hline 1 & 1 & -1 & 5240 \\
\hline 1 & -1 & 1 & 5664 \\
\hline 1 & -1 & -1 & 4864 \\
\hline
\end{tabular}

Table 3. Characteristic fault frequencies for dynamic AGE

which occurred already in all spectra of fans in delivery state. The minor change in the frequency is the result of changed rotor speed.

\subsubsection{Spectral Analysis for Rotor Unbalance Fault}

Two ways of fault insertion for the rotor unbalance fault are analysed in this section. Additional mass is attached in either the propeller of the fan and in the drill holes which are inserted by the manufacturer in order to balance the rotating mass.

A representative spectrum for these ways of inducing an unbalance is shown in Figure 20. The characteristic fault frequencies are slightly shifted compared to Table 3 since the

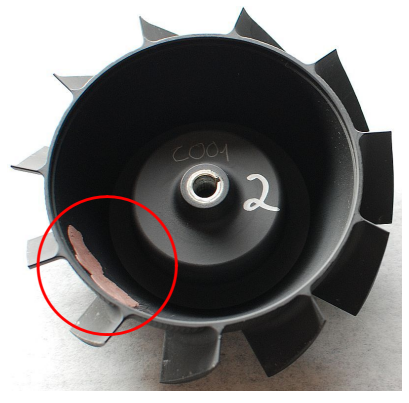

Figure 17. Mass in propeller

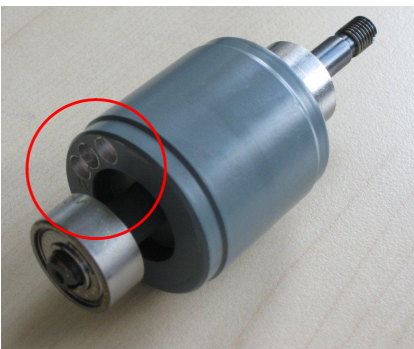

Figure 18. Drill holes rotor speed for this test run was $f_{\text {rotor }}=187.1 \mathrm{~Hz}$, giving the characteristic fault frequencies centred in the plots. Comparing this spectrum to the spectra shown in section 4 leads to the conclusion that a rotor unbalance of minor severity can not be detected using FFT based MCSA. Note especially the peak in the lowest plot at $4840 \mathrm{~Hz}$, which can be found in all spectra of fans in delivery state, although in some cases with lower current magnitude. This indicates, that the rotors are not balanced perfectly which was expected since no manufacturing process is perfect. Nevertheless, no difference between a motor in delivery state and a motor with additionally attached unbalancing mass can be detected in the spectra. The plots shown in Figure 20 was the one with the most mass attached. The mass was $1.5 \mathrm{~g}$, compared to a mass of $541 \mathrm{~g}$ for rotor and propeller. A more severe rotor unbalance appears in the broken rotor bar (BRB) tests. For these fault cases, holes were drilled in the rotor, as seen in Figure 19. This fault causes the rotor to be unbalanced since mass is removed asymmetrically. The spectrum for one drilled hole is shown in Figure 21 and the spectrum for three drilled holes is shown in Figure 22. Note the adjusted magnitude axes. Clearly, the peaks at some characteristic fault frequencies are increased in the first, second and last line of both figures. These features can be used to detect the rotor unbalance and furthermore, the damage level can be rated. Surely, the damage induced by drilling a hole in the rotor is artificial but this analysis proves that also for a fast rotating $400 \mathrm{~Hz}$ motor, a rotor unbalance can be detected

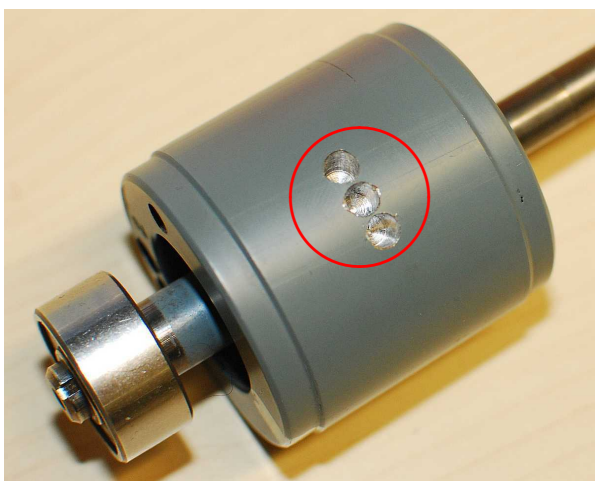

Figure 19. Rotor unbalance in BRB test 

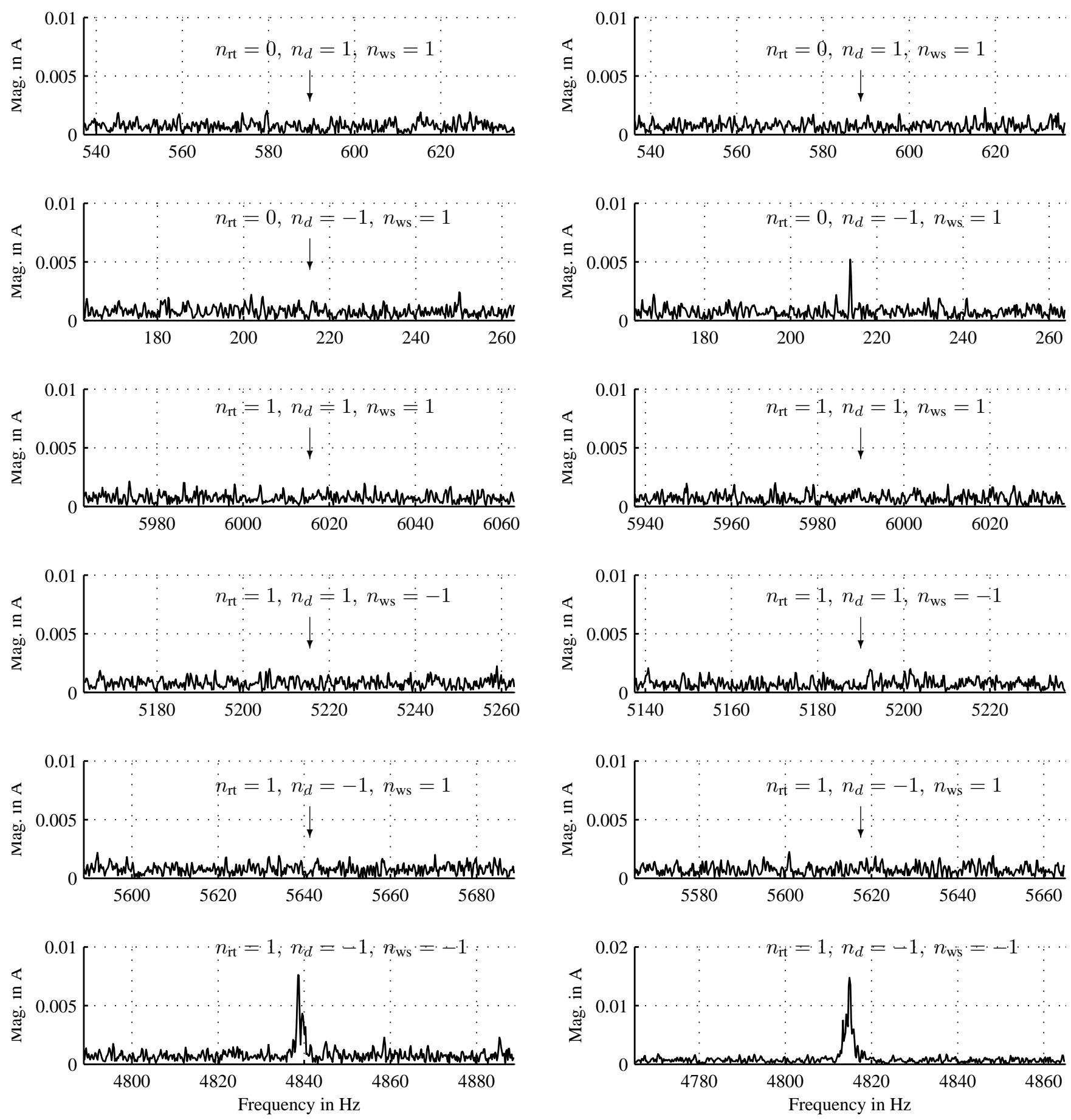

Figure 20. Additional unbalancing mass

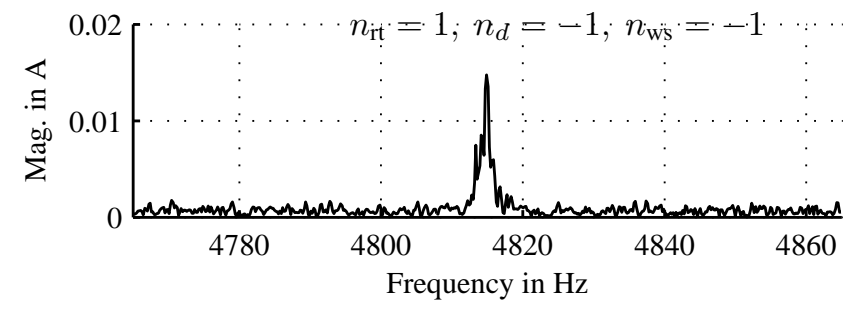

Figure 21. One broken rotor bar

\subsection{Stator Winding Fault}

The stator winding fault (STF) is a fault in the electrical part of the motor. Three different cases of the STF can occur in induction machines:

if the unbalance is high enough to cause a dynamic air gap eccentricity.

- short circuit between two coils of the same phase 


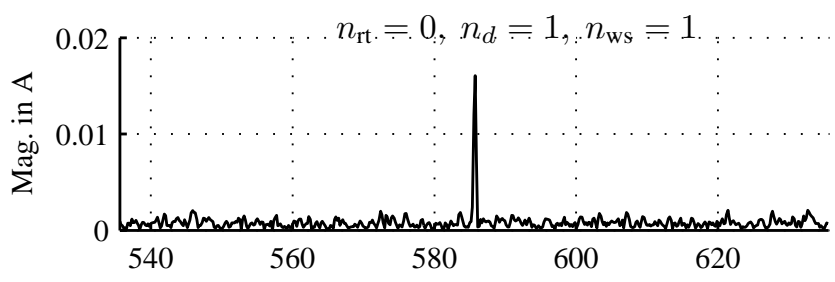

stator isolation is damaged by overheating, a short circuit can occur. Therefore, this fault case is artificially induced to the motor, see Figures 23.
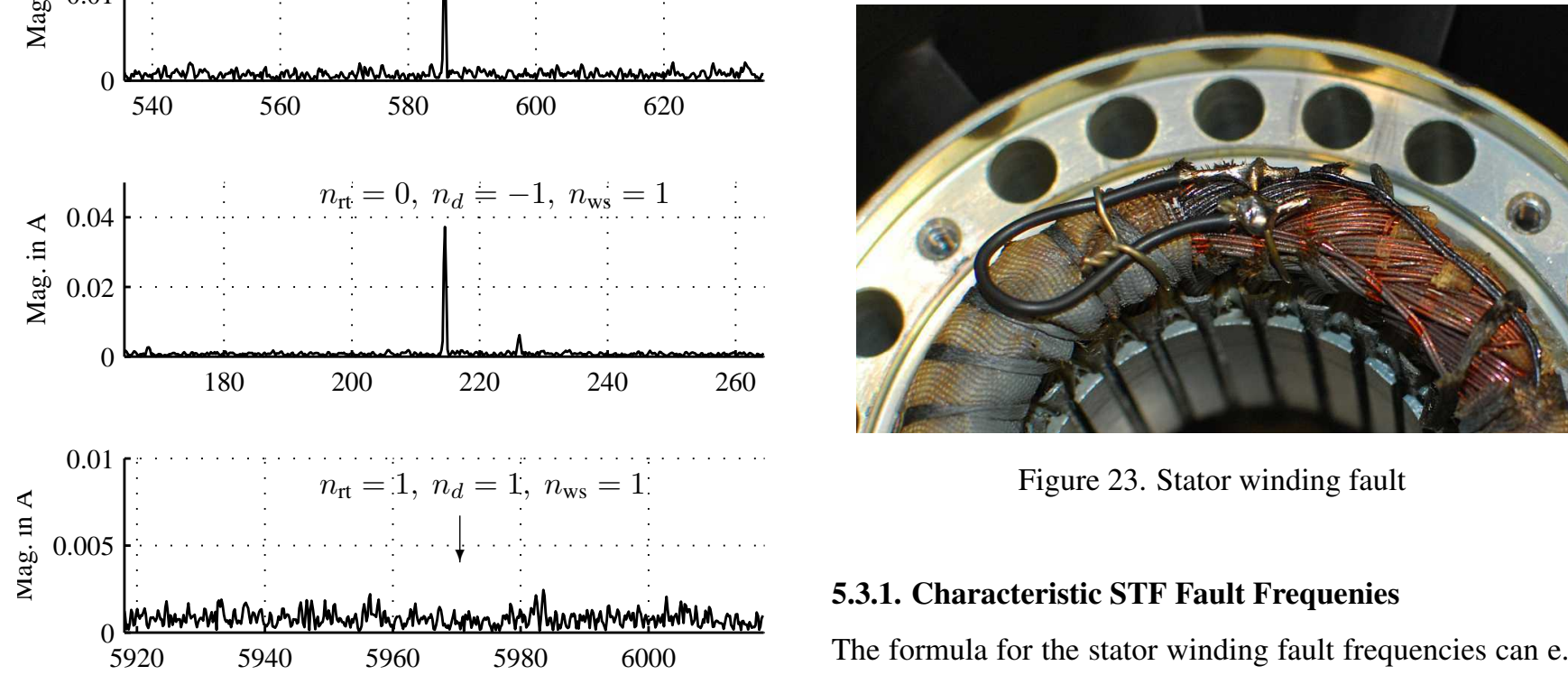

Figure 23. Stator winding fault

\subsubsection{Characteristic STF Fault Frequenies}

The formula for the stator winding fault frequencies can e.g. be found in (MEHALA, 2010; Thomson \& Gilmore, 2003) and is given by

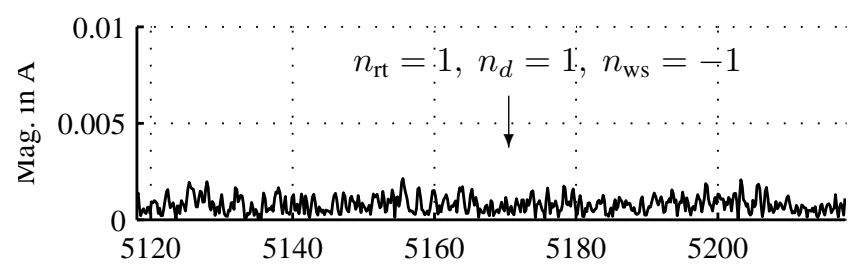

$$
f_{\mathrm{STF}}=\left(k_{\mathrm{STF}} \pm n_{\mathrm{STF}} \frac{1-s}{P}\right) \cdot f_{\mathrm{s}}
$$

$k_{\mathrm{STF}}$ and $n_{\mathrm{STF}}$ are any positive odd integers. Equation 9 is evaluated for a rotor speed of $181 \mathrm{~Hz}$ since the stator damage slightly reduces the motor speed. The characteristic fault frequencies are given in Table 4, whereof the absolute values of the frequencies are analysed.
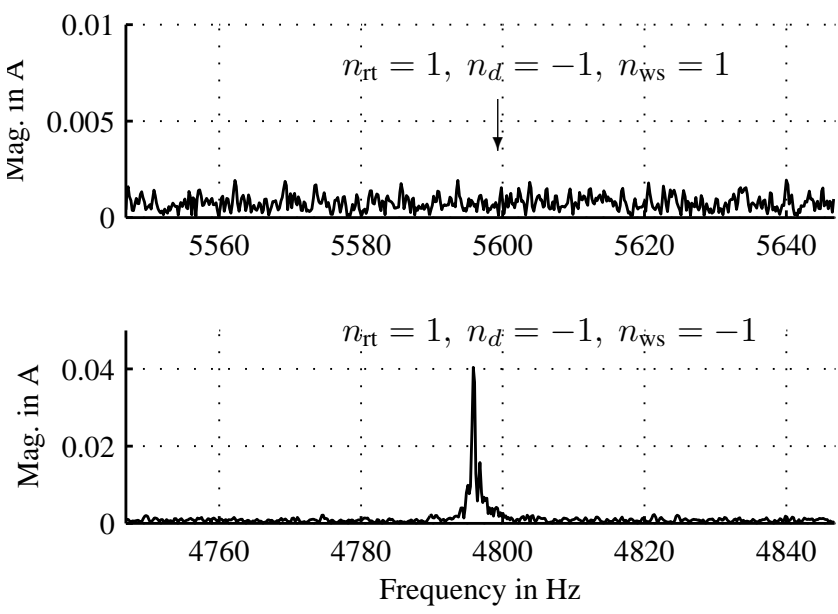

\begin{tabular}{c|c|c}
\hline \hline$k_{\text {STF }}$ & $n_{\text {STF }}$ & $f_{\text {STF }}$ in $\mathrm{Hz}$ \\
\hline \hline 1 & 1 & 581 \\
\hline 1 & -1 & 219 \\
\hline 1 & 3 & 943 \\
\hline 1 & -3 & -143 \\
\hline 3 & 1 & 1381 \\
\hline 3 & -1 & 1019 \\
\hline 3 & 3 & 1743 \\
\hline 3 & -3 & 657 \\
\hline
\end{tabular}

Table 4. Characteristic fault frequencies for dynamic AGE

\subsubsection{Spectral Analysis for Stator Winding Fault}

Figure 22. Three broken rotor bars

- short circuit between two windings of the same coil

- short circuit between two coils of different phases

The last fault case is most likely since the voltage potential between two stator phases is the highest. Particles and dirt intrude in the stator and may begin to melt. If in this case the

The spectrum for the stator winding fault is shown in Figure 24. Note the adjusted magnitude axis. Obviously, the fault can easily be detected. The maximum current magnitude is approximately $80 \mathrm{~mA}$ at $581 \mathrm{~Hz}$, which is much higher than in the spectra in delivery state, as shown in section 4 . Furthermore, other peaks at characteristic fault frequencies are distinctive. The peaks at $221,143,1381$ and $1019 \mathrm{~Hz}$ are also suitable for the detection of the STF. In summary, the detection of this particular fault case of the electrical part of this 

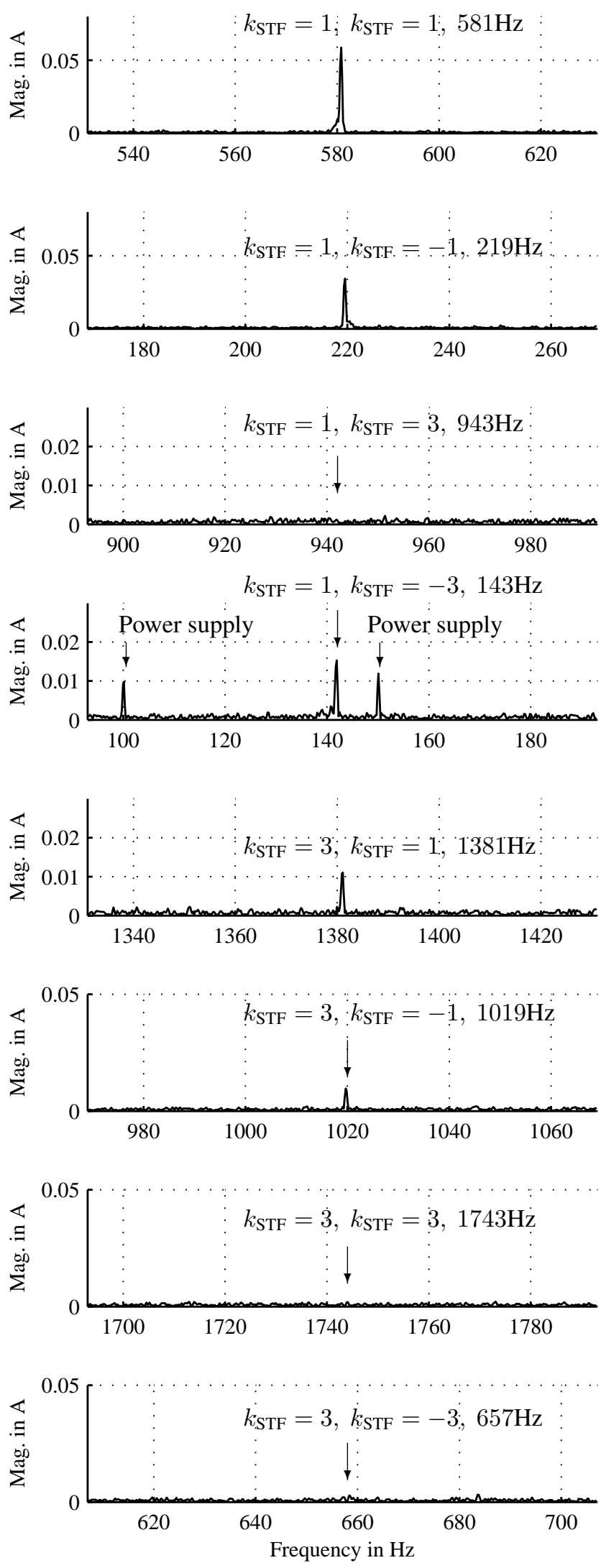

Figure 24. Spectrum for STF
$400 \mathrm{~Hz}$ airborne power supply motor is as good as for $50 / 60 \mathrm{~Hz}$ motors, as shown in the literature mentioned before.

\subsection{Broken Rotor Bar}

A broken rotor bar (BRB) is a fault in the electrical part of the rotor. This fault is artificially induced to the motor by drilling holes through the bars, see Figures 19. During operation, a BRB fault can e.g. occur due to overloading or due to mechanical stress causing cracks in the rotor.

\subsubsection{Characteristic BRB Fault Frequenies}

The formula for the BRB fault frequencies can e.g. be found in (Ayhan, Chow, \& Song, 2006; Haji \& Toliyat, 2001; MEHALA, 2010) and is given by

$$
f_{\mathrm{BRB}}=\left(1 \pm 2 k_{\mathrm{BRB}} \cdot s\right) \cdot f_{\mathrm{s}}
$$

$k_{\mathrm{BRB}}$ is any positive integer. Equation 10 is evaluated for a rotor speed of $186 \mathrm{~Hz}$, which is approximately the rotor speed during the BRB test. This gives a slip of $s=0.07$. The rotor speed slightly depends on the number of broken bars. The characteristic fault frequencies are given in Table 5.

\begin{tabular}{c|c}
\hline \hline$k_{\text {BRB }}$ & $f_{\text {BRB }}$ in $\mathrm{Hz}$ \\
\hline \hline 1 & 456 \\
\hline-1 & 344 \\
\hline 2 & 512 \\
\hline-2 & 288 \\
\hline 3 & 568 \\
\hline-3 & 232 \\
\hline
\end{tabular}

Table 5. Characteristic fault frequencies for BRB

\subsubsection{Spectral Analysis for Broken Rotor Bar}

Figure 25 shows the spectrum for a BRB fault with one rotor bar drilled through. Note the adjusted magnitude axes while comparing the peaks to those of motors in delivery state as shown in section 4. Clearly, the damaged rotor causes the characteristic fault frequencies of this failure case to be measurably increased. This means that this fault case can be detected even in case of very low damage level. Figure 26 shows the spectrum for increased damage level. For this test run, three rotor bars are drilled through, as shown in Figure 19. It is obvious, that the peaks at the characteristic frequencies are higher than in the test run with one damaged rotor bar, the magnitude axes are unchanged in this comparison. This proves that the features extracted from the Fourier transformed current signal can be used to determine the health grade of the rotor bars. The tests were repeated using the damaged rotor in three different motor housings. The results shown in this section could be confirmed. The current signature at the characteristic fault frequencies of a BRB depend on the damage grade of the rotor and are not affected by the stator. Since this particular fault case is non reversible, only 

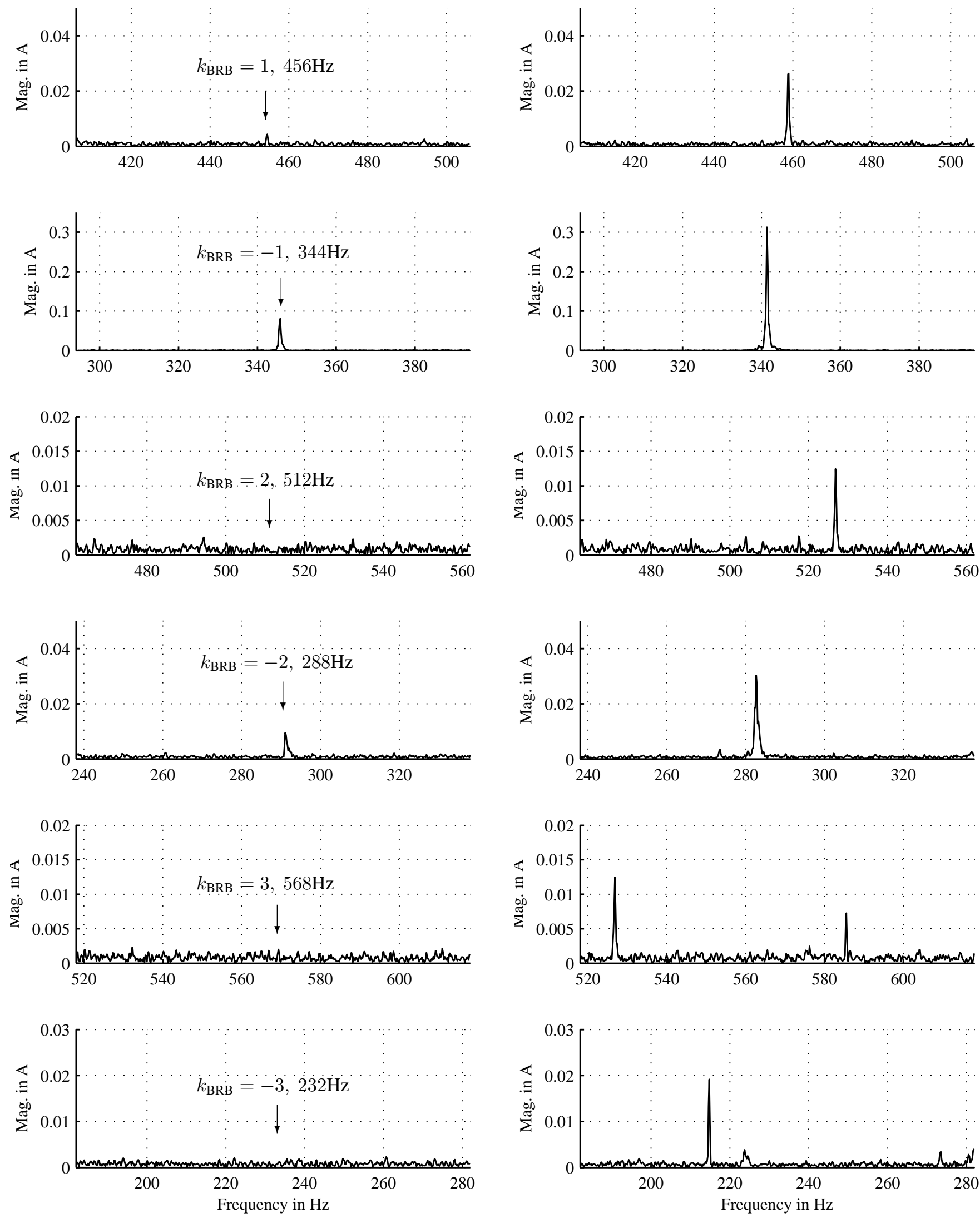

Figure 25. Spectrum for BRB, 1 bar

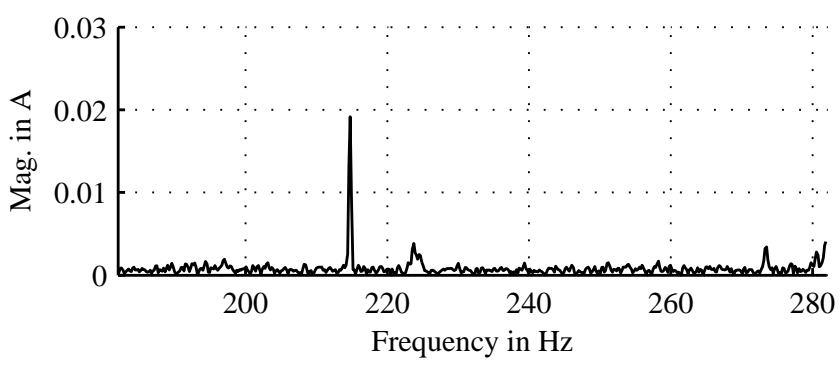

Figure 26. Spectrum for BRB, 3 bar 
one rotor was damaged. Nevertheless, the clear results and the transferability to different stators prove the results to be valid.

Furthermore, the presented results indicate that this fault case could be analysed concerning a prognosis algorithm. This could be useful for rotors with embedded rotor bars (like the one used for these tests), since if the rotor has a crack, it is likely that the crack spreads in case of mechanical stress.

\subsection{Static Air Gap Eccentricity}

A static air gap eccentricity (AGE) is a fault in the mechanical part of the motor. A static AGE occurs if rotor and stator are statically misaligned. This means that the rotation axis of the rotor is out of alignment to the stator axis. This causes changes in the magnetic flux, leading to an induced current which can be measured by monitoring the motor line currents. For the tests in this research work, the fault is artificially induced by installing spacers under the front bell. This causes the front bearing to be tilted. The spacers are installed in the screw holes, which can be seen in Figure 27. For the testing, different sized spacers at different number of screws were used, see Table 6.

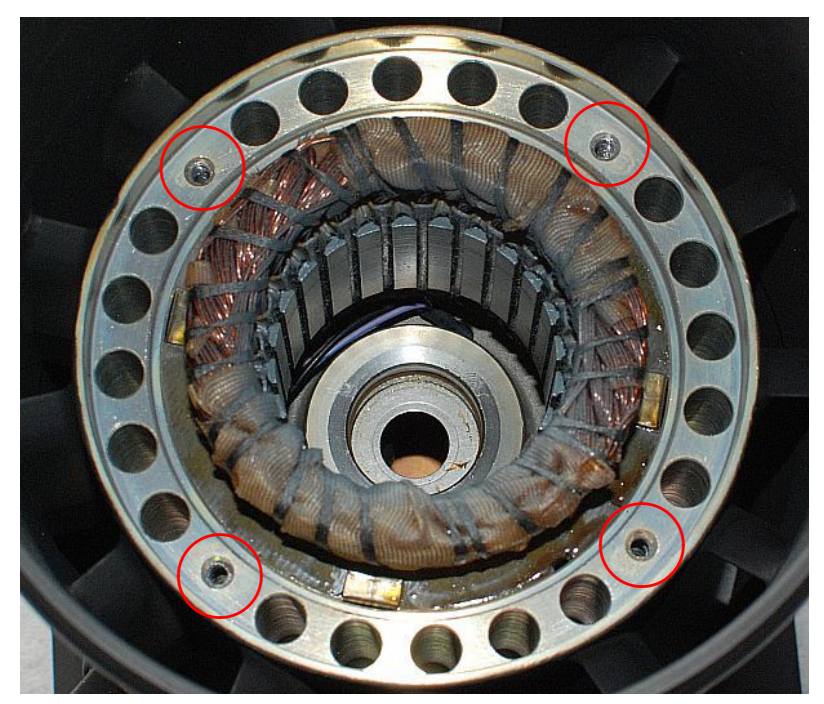

Figure 27. Static AGE fault

\begin{tabular}{c|c|c|c}
\hline \hline Index & $\begin{array}{c}\text { Spacer height } \\
\text { in mm }\end{array}$ & $\begin{array}{c}\text { No. of screws } \\
\text { with spacers }\end{array}$ & $\begin{array}{c}\text { Bearing } \\
\text { angle in degree }\end{array}$ \\
\hline \hline 1 & 0.5 & 1 & 0.33 \\
\hline 2 & 0.6 & 2 & 0.57 \\
\hline 3 & 1.0 & 1 & 0.69 \\
\hline
\end{tabular}

Table 6. Test setup for static AGE fault

\subsubsection{Characteristic Static AGE Fault Frequenies}

The formula for the static AGE fault frequencies are the same as for the dynamic AGE fault and are given by Equation 4 with $n_{\mathrm{d}}=0$. Evaluation of this formula for a rotor speed of $187 \mathrm{~Hz}$ gives the characteristic fault frequencies for the static AGE fault as given in Table 7. Since the first frequencies

\begin{tabular}{c|c|c|c}
\hline \hline$n_{\mathbf{r t}}$ & $n_{\mathbf{d}}$ & $n_{\mathbf{w s}}$ & $f_{\text {AGE,static }}$ in $\mathrm{Hz}$ \\
\hline \hline 0 & 0 & 1 & 400 \\
\hline 0 & 0 & -1 & -400 \\
\hline 0 & 0 & 3 & 1200 \\
\hline 0 & 0 & -3 & -1200 \\
\hline 1 & 0 & 1 & 5823 \\
\hline 1 & 0 & -1 & 5023 \\
\hline 1 & 0 & 3 & 6623 \\
\hline 1 & 0 & -3 & 4223 \\
\hline
\end{tabular}

Table 7. Characteristic fault frequencies for static AGE exactly match the supply frequency which is filtered, this frequency can not be used for diagnosis.

\subsubsection{Spectral Analysis for Static AGE Fault}

Figure 28 and Figure 29 show the spectra for the static AGE fault cases \#1 and \#3, as given in Table 6. The results in this section are measured using motor $\# 2$, whose reference spectrum is shwon in Figure 9. In delivery state, the peak at approx. $5023 \mathrm{~Hz}$ has a magnitude of less than $5 \mathrm{~mA}$. The magnitude of this frequency is increased with the spacers applied to the front bell. For test scenario \#1 the magnitude is approx. $7 \mathrm{~mA}$ and for scenario \#3 it is above $10 \mathrm{~mA}$. The static AGE fault can clearly be detected using the Fourier spectra of the line current. Furthermore, the damage grade can be evaluated. The frequency which can be used for detection of the static AGE fault clearly is around $5023 \mathrm{~Hz}$ since the other peaks show no modification due to the spacers.

Finally it has to be mentioned, that in some cases the motors in delivery status show a significant peak at this frequency, see e.g. Figure 7 for motor \#1. In this test run, the magnitude at approx. $5000 \mathrm{~Hz}$ is almost as high as the one in this chapter for test scenario \#3. Due to the exact motor housing, no further deflection of the front bell could be achieved since the fan would scratch on the motor housing. The damage level in these tests was very low, nevertheless, the static AGE fault can be detected. 

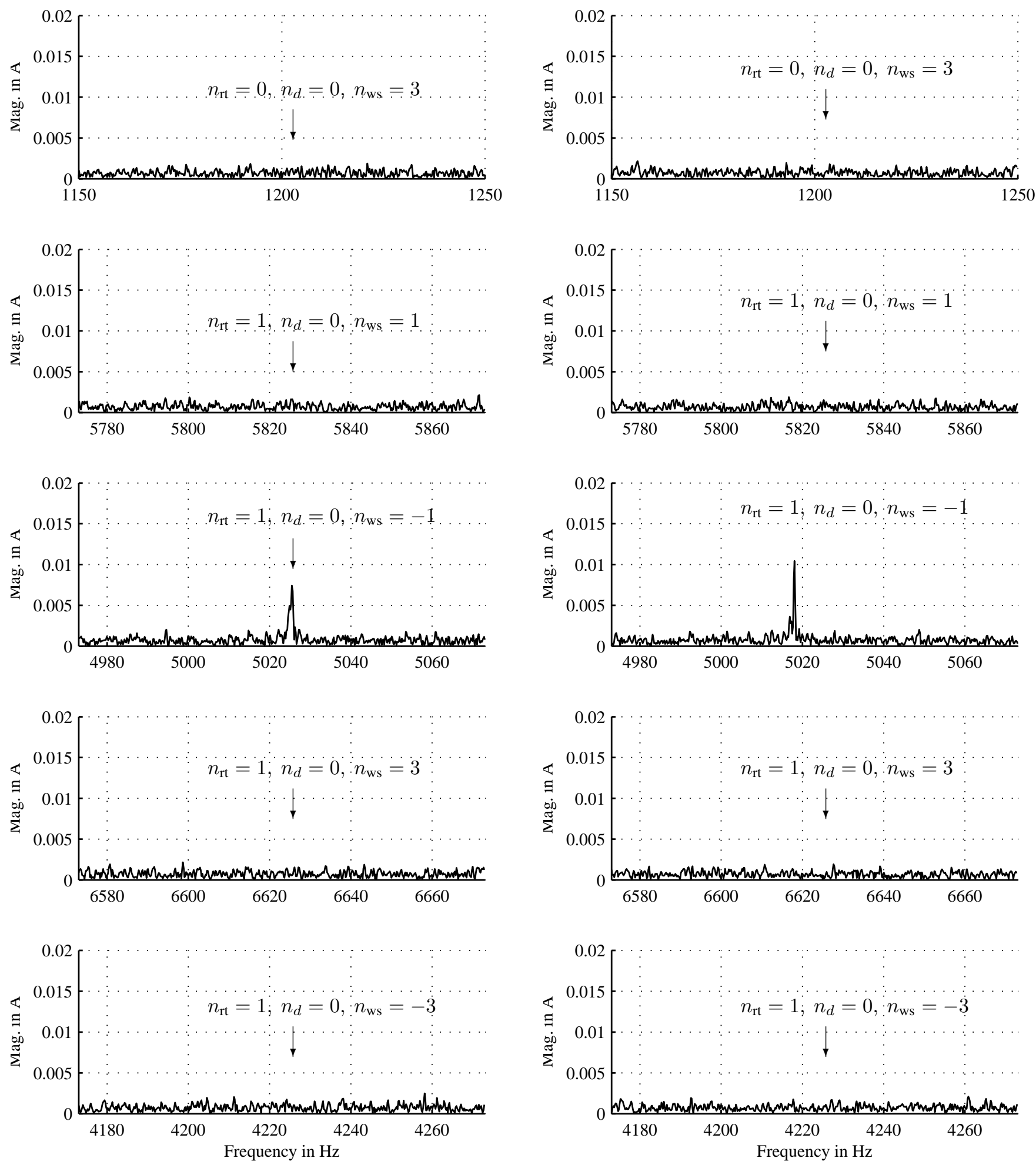

Figure 28. Static AGE case \#1

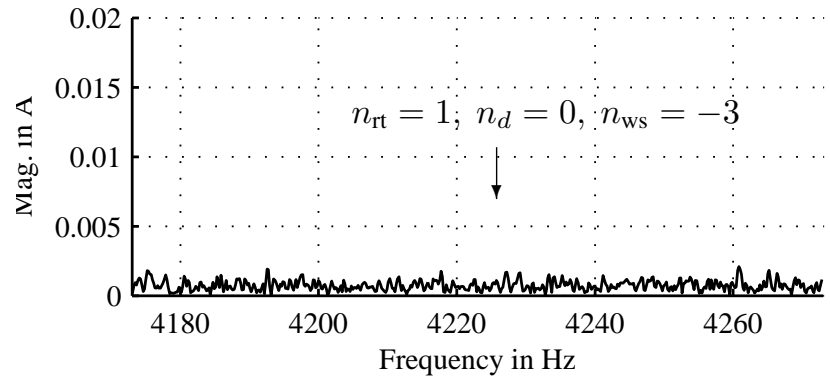

Figure 29. Static AGE case \#3 


\section{Conclusion}

In this research work, the transferability of the very common approach of FFT based MCSA from $50 / 60 \mathrm{~Hz}$ induction motors to a small size aircraft certificated $400 \mathrm{~Hz}$ asynchronous motor was analysed. The small size high quality motor showed some major drawbacks concerning the possibility of health assessment compared to standard industry motors with $50 / 60 \mathrm{~Hz}$ power supply. The features selected for diagnosis of the motor health grade are the current magnitude of the characteristic fault frequencies of the respective failure cases. These were bearing fault, rotor unbalance, stator winding fault, broken rotor bar and static air gap eccentricity, which are the expected failure cases causing an induction machine to fail. Experiments were carried out on different motors for all but one fault case, allowing a statement on the deviation of the motor current signature due to manufacturing inaccuracy. The measurement concept proposed in this research work allows for fault detection using current sensors only.

The increased motor speed and the decent build quality of the aircraft certificated motor is assumed to be the reason that the bearing fault could not be detected using the proposed sensor configuration. Based on literature survey, some indepth diagnosis methods are suggested for health monitoring. Such concepts are still to be analysed for the $400 \mathrm{~Hz}$ motor.

Rotor unbalance could be detected if the unbalancing mass is high enough. In this case, a considerably severe damage grade could be detected. Small unbalance levels could not be detected due to the comparatively solid rotor design and therefore small changes in the air gap between stator and rotor.

Both fault cases affecting the electrical system of the motor, the stator winding fault and broken rotor bars, could be detected reliably. In case of the broken rotor bars, differences dependent on the number of broken bars, could clearly be identified in the Fourier spectra of the current signal.

Static air gap eccentricity could also be detected reliably. Nevertheless, concerning this fault case, a misinterpretation is possible since the peaks at the characteristic fault frequencies are very small but measured data proved that even the health grade for this fault case could be estimated.

The research work showed, that all faults in the electrical part of the motor could be detected reliably. The results of $50 / 60 \mathrm{~Hz}$ motors can be transferred to this small size, high quality and fast rotating $400 \mathrm{~Hz}$ motor. The experiments demonstrate that fault detection in the electrical part of $400 \mathrm{~Hz}$ induction machines can be integrated in a health monitoring system for airborne applications. This is suggested with the intention of avoiding unscheduled downtime. In case of mechanical degradation, a fault detection is much more difficult and, especially in case of a bearing fault, not possible using the Fourier transformation of the current signal only. For this fault case, the application and testing of more sophisticated diagnosis algorithms is suggested in order to integrate the detection of mechanical faults in a future health monitoring concept. This subject is currently being researched.

\section{NOMENCLATURE}

\section{Symbols}

$f_{\text {AGE,dyn }}$ Characteristic Fault Freq. for Dynamic AGE

$f_{\text {AGE,static }}$ Characteristic Fault Freq. for Static AGE

$f_{\mathrm{BRB}} \quad$ Characteristic Fault Freq. for BRB Fault

$f_{\mathrm{BRG}} \quad$ Characteristic Fault Freq. for Bearing Fault

$f_{\text {iror }} \quad$ Characteristic Freq. inner/outer Bearing Ring

$f_{\mathrm{r}} \quad$ Rotor Speed

$f_{\text {STF }} \quad$ Characteristic Fault Freq. for STF

$f_{\mathrm{s}} \quad$ Supply Frequency

$I_{\mathrm{a}, \mathrm{b}, \mathrm{c}} \quad$ Line Current

$k_{\mathrm{BRB}} \quad$ Index for BRB Fault Frequencies

$k_{\mathrm{STF}} \quad$ Index for STF Frequencies

$m \quad$ Index for BRG Fault Frequencies

$N_{\mathrm{b}} \quad$ Number of Bearing Balls

$n_{\mathrm{d}} \quad$ Eccentric Order for AGE Fault Frequency

$n_{\mathrm{rt}, \mathrm{ws}} \quad$ Indices for AGE Fault Frequencies

$n_{\mathrm{STF}} \quad$ Index for STF Frequencies

$P \quad$ Pole Pairs

$R \quad$ Number of Rotor Bars

$s \quad$ Slip

$\omega \quad$ Rotor Speed

\section{Abbreviations}

$\begin{array}{ll}\text { AGE } & \text { Air Gap Eccentricity } \\ \text { BRB } & \text { Broken Rotor Bar } \\ \text { BRG } & \text { Bearing } \\ \text { FFT } & \text { Fast Fourier Transformation } \\ \text { MCSA } & \text { Motor Current Signature Analysis } \\ \text { PHM } & \text { Prognostics and Health Management } \\ \text { STF } & \text { Stator Winding Fault } \\ \text { SNR } & \text { Signal to Noise Ratio }\end{array}$

\section{REFERENCES}

Ayhan, B., Chow, M., \& Song, M. (2006). Multiple discriminant analysis and neural-network-based monolith and partition fault-detection schemes for broken rotor bar in induction motors. Industrial Electronics, IEEE Transactions on, 53(4), 1298-1308.

Benbouzid, M., \& Kliman, G. (2003). What stator current processing-based technique to use for induction motor rotor faults diagnosis? Energy Conversion, IEEE Transactions on, 18(2), 238-244.

Ben Salem, S., Bacha, K., \& Gossa, M. (2012). Induction mo- 
tor fault diagnosis using an improved combination of Hilbert and Park transforms. In Electrotechnical Conference (MELECON), 2012 16th IEEE Mediterranean (pp. 1141-1146).

Blodt, M., Granjon, P., Raison, B., \& Rostaing, G. (2008). Models for bearing damage detection in induction motors using stator current monitoring. Industrial Electronics, IEEE Transactions on, 55(4), 1813-1822.

El Hachemi Benbouzid, M. (2000). A review of induction motors signature analysis as a medium for faults detection. Industrial Electronics, IEEE Transactions on, 47(5), 984-993.

Fritzsche, R., \& Lasch, R. (2012). An Integrated Logistics Model of Spare Parts Maintenance Planning within the Aviation Industry. In Proceedings of world academy of science, engineering and technology (Vol. 68).

Haji, M., \& Toliyat, H. (2001). Pattern recognition-a technique for induction machines rotor broken bar detection. Energy Conversion, IEEE Transactions on, 16(4), 312-317.

Knotts, R. (1999). Civil aircraft maintenance and support Fault diagnosis from a business perspective. Journal of quality in maintenance engineering, 5(4), 335-348.

Lau, E., \& Ngan, H. (2010). Detection of motor bearing outer raceway defect by wavelet packet transformed motor current signature analysis. Instrumentation and Measurement, IEEE Transactions on, 59(10), 2683-2690.

Marques Cardoso, A., Cruz, S., \& Fonseca, D. (1999). Interturn stator winding fault diagnosis in three-phase induction motors, by Park's vector approach. Energy Conversion, IEEE Transactions on, 14(3), 595-598.

MEHALA, N. (2010). Condition monitoring and fault diagnosis of induction motor using motor current signature analysis. Unpublished doctoral dissertation, National Institude of Technology Kurukshertra, India.

Nandi, S., Toliyat, H., \& Li, X. (2005). Condition monitoring and fault diagnosis of electrical motors-a review. Energy Conversion, IEEE Transactions on, 20(4), 719729.

Saadaoui, W., \& Jelassi, K. (2008). Gearbox-induction machine bearing fault diagnosis using spectral analysis. In Computer Modeling and Simulation, 2008. EMS'08. Second UKSIM European Symposium on (pp. 347-352).

Schoen, R., Habetler, T., Kamran, F., \& Bartfield, R. (1995).
Motor bearing damage detection using stator current monitoring. Industry Applications, IEEE Transactions on, 31(6), 1274-1279.

Thomson, W. (2001). On-line MCSA to diagnose shorted turns in low voltage stator windings of 3-phase induction motors prior to failure. In Electric Machines and Drives Conference, 2001. IEMDC 2001. IEEE International (pp. 891-898).

Thomson, W., \& Gilmore, R. (2003). Motor current signature analysis to detect faults in induction motor drivesfundamentals, data interpretation, and industrial case histories. In Proceedings of the thirty-second turbomachinery symposium (pp. 145-156).

Thomson, W., Rankin, D., \& Dorrell, D. (1999). On-line current monitoring to diagnose airgap eccentricity in large three-phase induction motors-industrial case histories verify the predictions. Energy Conversion, IEEE Transactions on, 14(4), 1372-1378.

\section{BIOGRAPHIES}

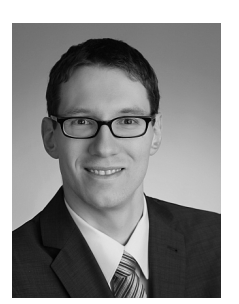

Steffen Haus was born in Dieburg, Germany, in 1981. He received his diploma degree in mechanical engineering from Technische Universität Darmstadt, Germany, in 2007. From 2007 he worked as research associate with Prof. Klingauf at Technische Universität Darmstadt at the Institute of Flight Systems and Automatic Control. His work covered system identification, modelling of human behaviour and model based control. His current research activities are focussed on model based control of flying robots and condition based maintenance of electrical motors.

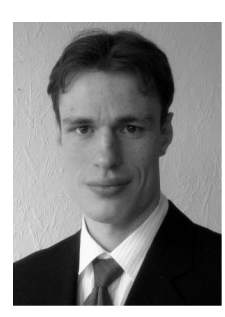

Heiko Mikat was born in Berlin, Germany, in 1979. He received his diploma degree in aeronautical engineering from the Technical University of Berlin, Germany, in 2008. From 2006 he worked as trainee and later on as Systems Engineer at RollsRoyce Deutschland, Berlin, Germany, designing and testing engine fuel system concepts and control laws. Since 2009 he works as Systems Engineer at the CASSIDIAN Supply Systems and Propulsion Department and is responsible for the development of new health management technologies for aircraft systems. His current research activities are mainly focussing on the maturation of failure detection and prediction capabilities for electrical, mechanical and hydraulic aircraft equipment. 


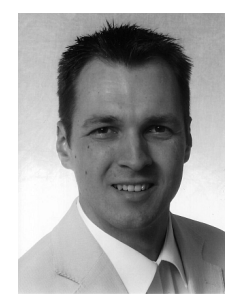

Martin Nowara was born in Erbach, Germany, in 1982. He received his diploma degree in computer science from Technische Universität Darmstadt, Germany, in 2009. From 2009 he worked as research associate with Prof. Klingauf at Technische Universität Darmstadt at the Institute of Flight Systems and Automatic Control. His work covered development and implementation of sensor data fusion algorithms on several hardware platforms, e.g. flying robots. His current research activities are focussed on environment modelling using optical sensors and the optimisation of navigation algorithms with low-cost sensor configurations.

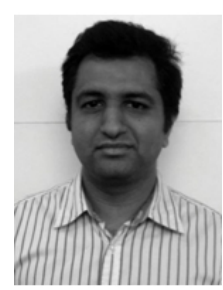

Surya Teja Kandukuri was born in Vijayawada, India in 1981. He received his masters degree in Systems \& Control from Delft University of Technology, Delft, The Netherlands in 2006. From 2007 he worked as an engineer in remote prognostics at General Electric Global Research, Bangalore India, designing diagnostic systems for power production equipments. Since 2011, he is working as an engineer with CASSIDIAN India, Bangalore and is responsible for development of diagnostics \& prognostics algorithms for aircraft components. His current research activities are mainly focused on development of methods for quantifying crack propagation in metal components and diagnostics for electrical machinery.

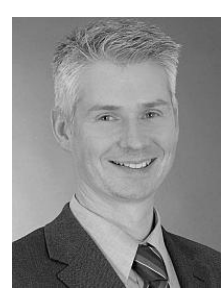

Uwe Klingauf, born 1963 in Bonn, Germany, studied Mechanical Engineering at Technische Universitt Darmstadt and received a doctors degree in 1995. From 1995 he worked for EADS (formerly Dasa), were he started as a Systems Engineer for Flight Control Systems. From 1997 he was put in charge of different managerial functions in Flight Guidance. From 2002 he was Vice President and responsible for several air defense programs. In 2004 he was appointed to the professorship at TU Darmstadt, where he heads the Institute of Flight Systems and Automatic Control. His main research interests are condition based maintenance systems, automation of flight and human factors.

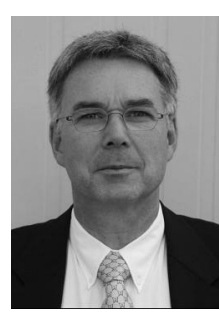

Matthias Buderath - Aeronautical Engineer with more than 25 years of experience in structural design, system engineering and product- and service support solution design. His main expertise and competence is related to system integrity management, service solution architecture and integrated system health monitoring and management.

Today he is head of technology development in CASSIDIAN and leads the ISHM program for UAS. He is member of international Working Groups covering Through Life Cycle Management, Integrated System Health Management and Structural Health Management. He has published more the 50 papers in the field of Structural Health Management, Integrated Health Monitoring and Management, Structural Integrity Programme Management and Maintenance and Fleet Information Management Systems. 